\title{
COLMENARES (L'ALACANTÍ), UN HÁBITAT IBÉRICO DE LLANURA EN ÉPOCA PLENA
}

\author{
COLMENARES (L'ALACANTÍ), AN IBERIAN PLAIN HABITAT IN THE MIDDLE IBERIAN PERIOD
}

JESÚS MORATALLA JÁVEGA

Universidad de Alicante

Arquealia

GABRIEL SEGURA HERRERO

Arquealia

La excavación arqueológica del yacimiento de Colmenares ha devenido en un paradigma de actuación preventiva al socaire del desarrollo urbanístico, localizando y excavando por completo un hito arqueológico ibérico desconocido hasta ese momento. En efecto, el proceso de investigación comienza con una prospección arqueológica superficial, que localiza las concentraciones cerámicas; continúa con una prospección mecánica, que documenta restos constructivos y los delimita en su extensión; y finaliza con la excavación íntegra del espacio determinado por la posición tanto de los sondeos positivos como de los inmediatos negativos.

\section{ANTECEDENTES HISTÓRICOS DE LA ZONA}

El área que albergaba en superficie un registro cerámico tan homogéneamente ibérico apenas había deparado hasta el momento noticia alguna de carácter arqueológico, siendo una de las zonas del término municipal de Alicante menos conocidas en este sentido (Fig. 1), sin duda por la carencia de prospecciones arqueológicas metódicas.

La única referencia localizada y relacionada con los terrenos objeto de estudio la recoge E. Llobregat (1991, 353), quién relata el hallazgo casual de una moneda altoimperial romana - un denario de época augustea datado hacia el 19-15 a.C.- «en el Bacarot [...]. En la partida dels Reiets», sin concretar más. Dicha partida se localiza a unos $2 \mathrm{~km}$ al nordeste del punto ahora excavado, por lo que parece un dato poco trascendente para los intereses que ahora nos mueven.

Relacionado con su carácter de lugar de paso, la zona es incluida en varios trabajos como área atravesada por un ramal de la Via Augusta; concretamente, G. Morote localiza la citada vía en la carretera que atraviesa el núcleo de Bacarot (Morote, 2002, 152), desde el Portichuelo hasta alcanzar la nacional N-330 -hoy llamada AP-7-. Al margen de otro tipo de consideraciones, lo cierto es que la fotografía aérea antigua

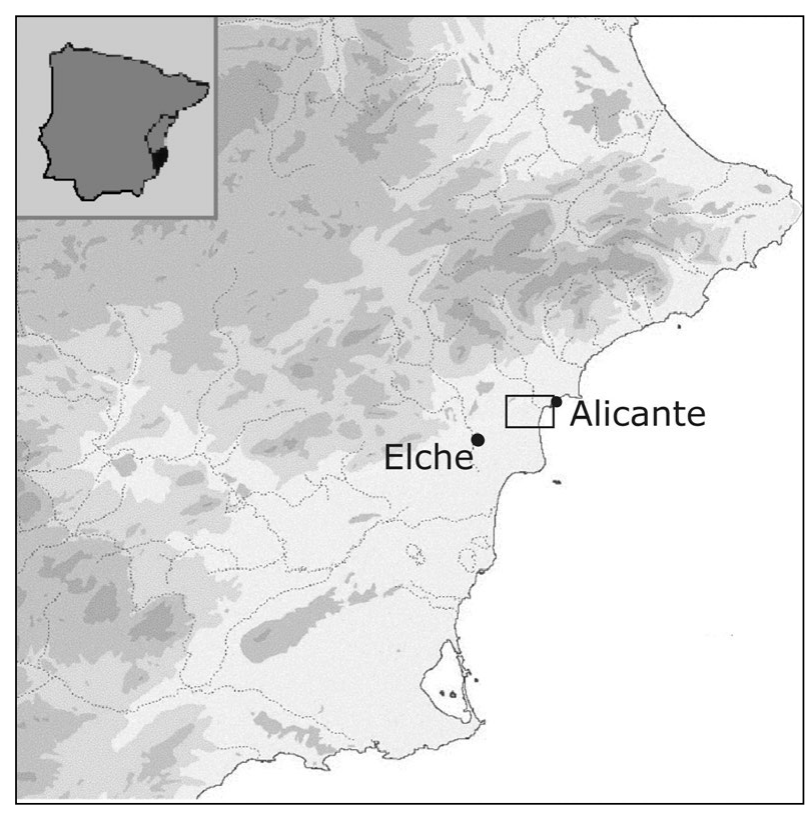

Figura 1: Localización del área intervenida en el ámbito provincial de Alicante.

permite concluir que la citada carretera es más moderna que el Camino Viejo de Elche -del que más adelante trataremos-, luego difícilmente se dataría en época romana, a no ser que admitamos que este último es incluso anterior; ello no es imposible, pero necesariamente habría que documentarlo con estudios de más largo alcance, que no son ahora objeto de nuestro relato.

Finalmente, no podemos obviar la existencia del propio topónimo de la partida, Bacarot, pues ha sido, desde los primeros estudios sobre lenguas prerromanas, firme candidato a formar parte de la toponimia ibérica $^{1}$, pues dicha voz -en su forma Bagarok- aparece

1. Algunos autores defienden su origen árabe (García Sempere, 1990, 172), en nuestra opinión mediante una más que forzada interpretación fonética. 


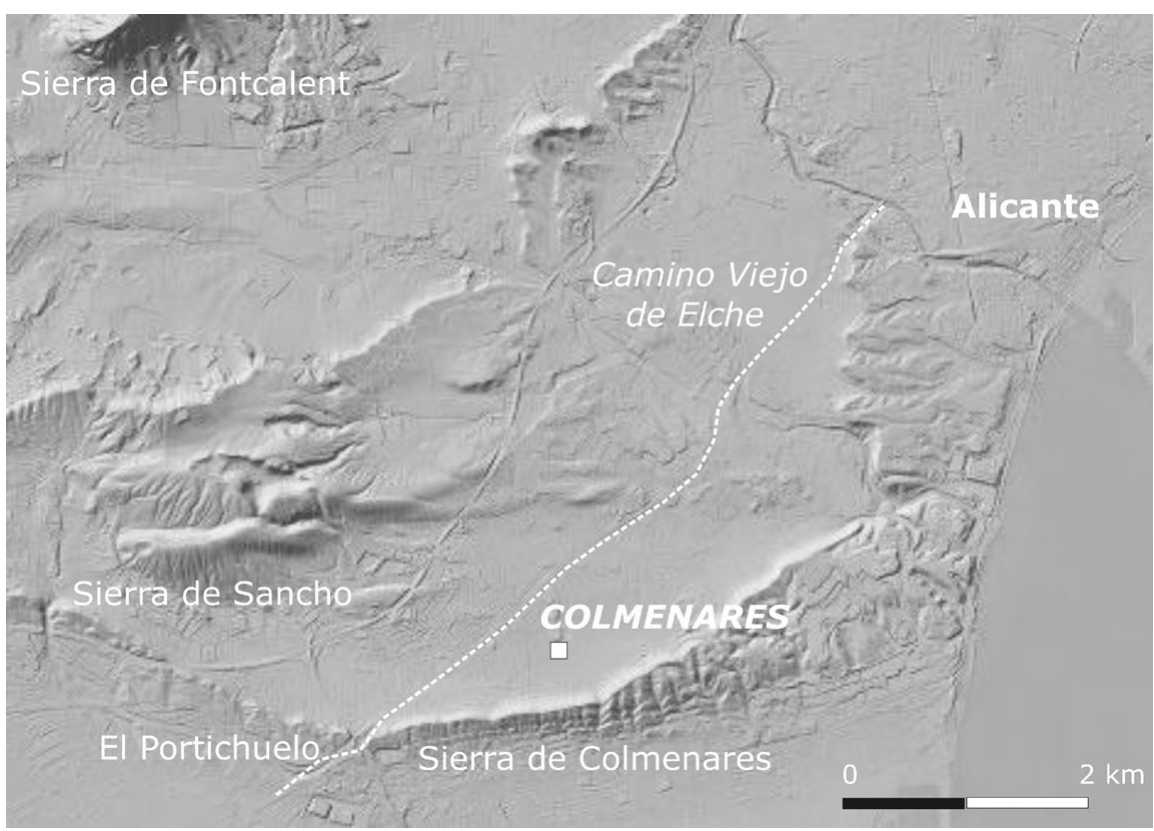

Figura 2: Ubicación de los restos arqueológicos en la partida de Bacarot.

transcrita prácticamente igual en varios textos epigráficos, sin ir más lejos el Plomo I de La Serreta (Fletcher y Silgo, 1992). De asumir esta interpretación lingüística, sería una variable histórica al menos a considerar, y habría que convenir, cuanto menos, que estaríamos ante un lugar identificado dentro de un paisaje ibérico, a caballo entre l'Alacantí y el Baix Vinalopó.

\section{LOCALIZACIÓN DEL ÁREA INTERVENIDA}

La excavación arqueológica realizada en este punto intermedio del viejo camino que antaño conectó Alicante y Elche (Fig. 2) surge como consecuencia derivada de un proyecto para ampliar las instalaciones de un campo de golf. El asentamiento de Colmenares fue localizado mediante una prospección sistemática de superficie ${ }^{2}$, dentro de un conjunto de bancales situados en el piedemonte de la sierra homónima, en un área de unos $6.000 \mathrm{~m}^{2}$ de dispersión de material cerámico. Este nivel de base, llano, se eleva unos 70-80 m en su flanco meridional, la sierra de Colmenares propiamente dicha, una modesta alineación englobada en un arco montañoso sudoeste-nordeste que se extiende desde el litoral hasta la sierra de Sancho, marcando la divisoria natural entre los municipios alicantino e ilicitano. A pesar de su escasa cota cimera (116 m s.n.m.), la sierra establece una clara distinción de unidades de relieve a uno y otro lado de la misma: mientras la umbría muestra un paisaje típico del secano mediterráneo, a

2. Intervención arqueológica autorizada por la Dirección General de Patrimonio Cultural de la Generalitat Valenciana, en fecha 12 de febrero de 2008, con el expediente $n^{\circ}$ 2008/0076-A. los pies de su solana se extendía el Saladar de Aguamarga, que hasta hace unas décadas aún se explotaba como salina.

Como elemento de conexión de ambas unidades, el Camino Viejo de Elche $e^{3}$ pasa a unos $500 \mathrm{~m}$ al norte del yacimiento, constituyéndose como un factor a considerar dada su antigüedad, como delatan las fuentes escritas (Blasco et alii, 1999). El trazado de esta ruta, por otro lado, nunca corta parcelas, -lo que suele resultar muy significativo-, además de dirigirse hacia el Portitxol $^{4}$, un paso abierto en la sierra documentado en los siglos XIII (del Estal, 1990, 22) y XIV (Ferrer i Mallol, 1988, 65, 189).

Finalmente, el conjunto ahora excavado se localiza inmediatamente al oeste de una pista caminera muy perdida pero que merece la pena subrayar; por ella se alcanza, primero, una caseta de labranza y, poco después, se eleva para salvar la sierra de Colmenares por un estrecho collado. El dato resulta sugestivo para justificar mejor el emplazamiento de esta construcción.

Volviendo al área de intervención (Fig. 3), el terreno se define como un conjunto de parcelas rectangulares orientadas de este a oeste, con diferencias de cota entre ellas de 40-50 cm. Las más meridionales $-\mathrm{y}$ cercanas a la sierra- se sitúan a unos 50 m s.n.m., descendiendo hasta los $46 \mathrm{~m}$ en las más septentrionales, resultando una pendiente media del 2-3\%, una tasa que subraya el carácter eminentemente llano del lugar.

3. En algunos documentos cartográficos también es denominado Camí Vell d'Oriola.

4. El topónimo aún aparece en 1947 en la cartografía oficial a escala 1:50000 del Servicio Geográfico del Ejército. Por su parte, el conocido mapa de F. Coello añade al topónimo «S. del Portichuelo», un segundo referente también significativo: Paso del Bou (Coello, 1859). 


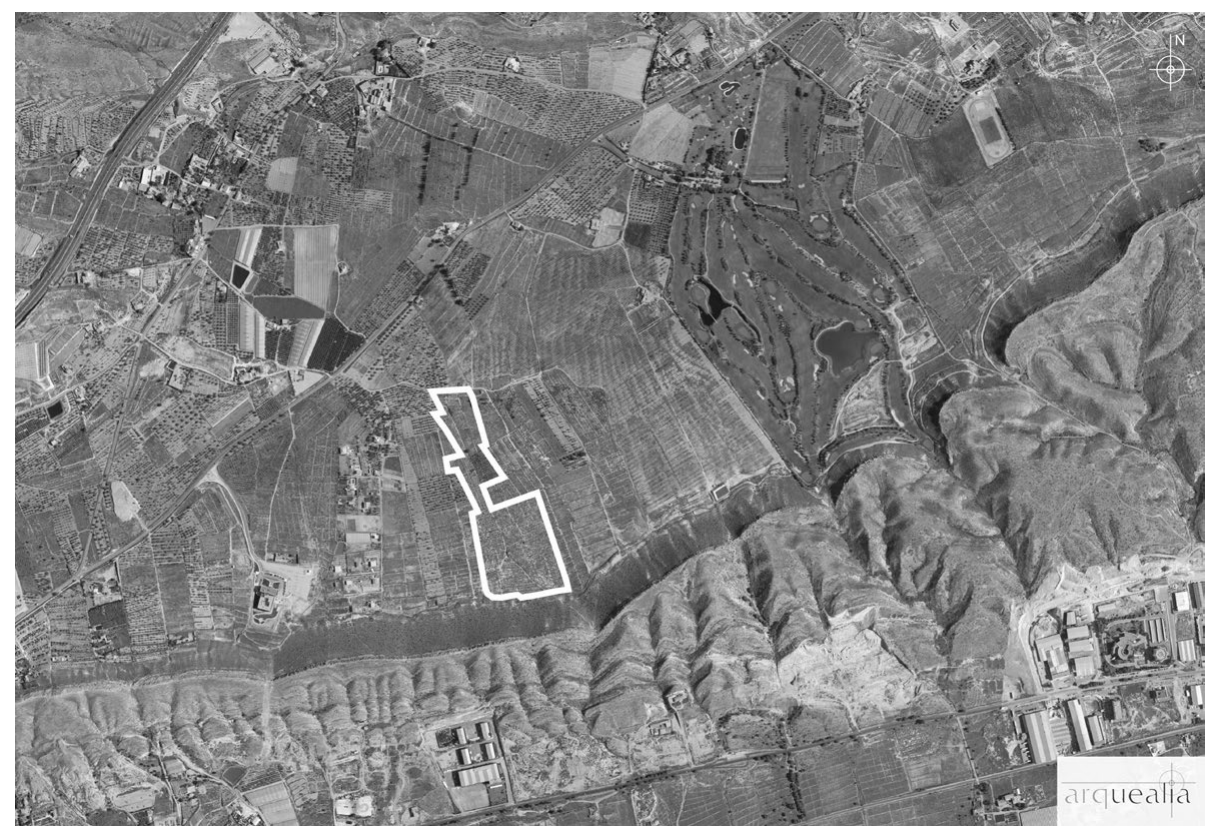

Figura 3: Delimitación del registro cerámico superficial.

Son tierras de secano tradicional, aunque hoy apenas subsisten algunas parcelas con almendros y una vegetación relicta que recuerda la existencia pasada de cereal. El sustrato edáfico presenta por su parte un importante espesor, sin presencia destacada de cantos ni alta salinidad, llegando a ser calificados como de calidad B en los estudios de calidad de suelos realizados (Gumuzzio y Matarredona, 1983, 40, figs. 2 y 4), por lo que ofrecen un buen punto de partida para su explotación económica.

En estas parcelas donde se detecta el asentamiento a nivel superficial, se dispusieron, a modo de peine,
18 sondeos para determinar su emplazamiento exacto, siendo concretamente las zanjas 6 y 7 las que dieron con la construcción ibérica; a partir de esta información se delimitó un área de unos $350 \mathrm{~m}^{2}$ de superficie, que fue excavada íntegramente (Fig. 4). Casualidad o, más bien, no, una de las muy escasas evidencias de terraza de mampostería localizada en el parcelario -un recio muro de más de $1 \mathrm{~m}$ de altura-, engloba en su interior los restos arquitectónicos excavados. Este hecho podría derivar de la presencia en el subsuelo del asentamiento, que ha podido proporcionar los mampuestos empleados en esta terraza.

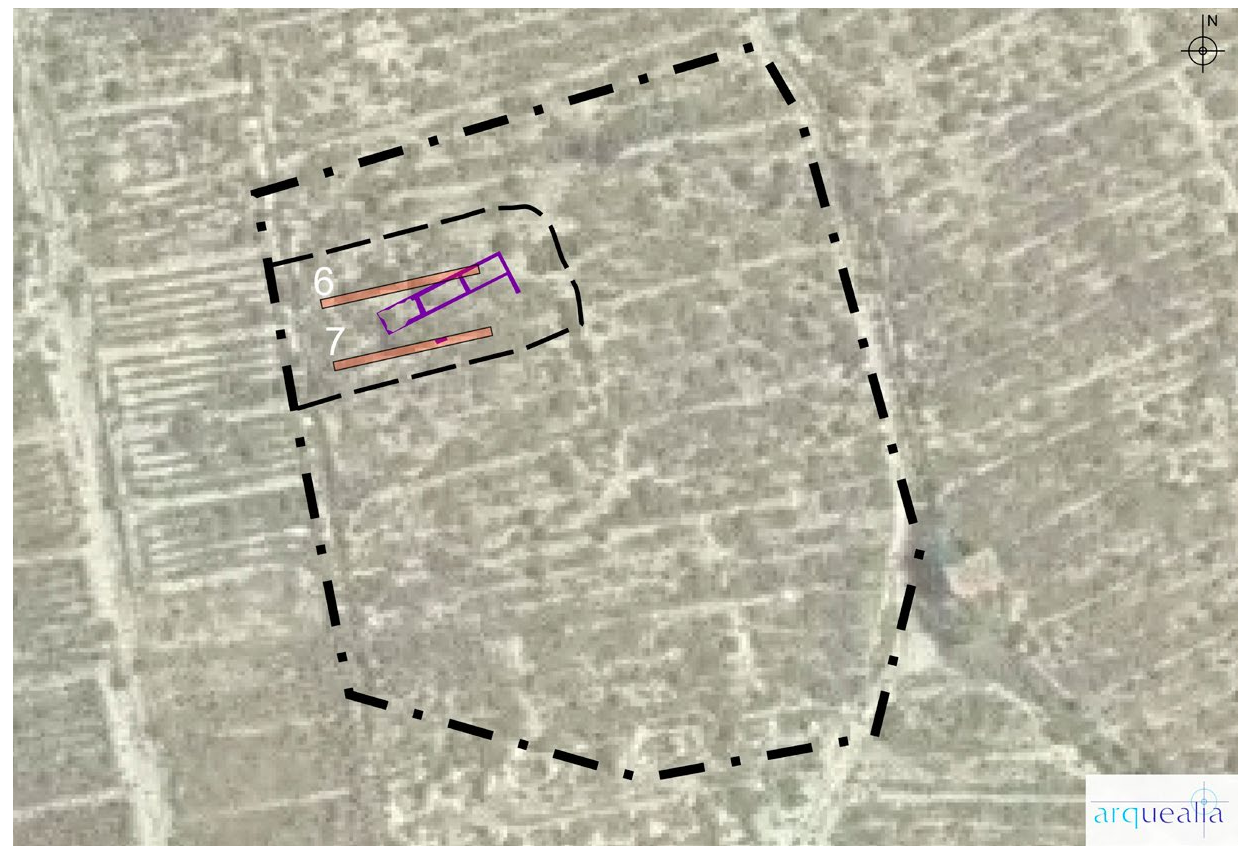

Figura 4: Localización de la construcción a partir de los sondeos mecánicos. 


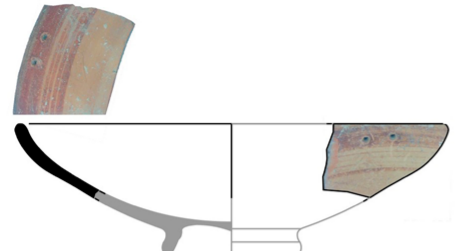

UE 100-1

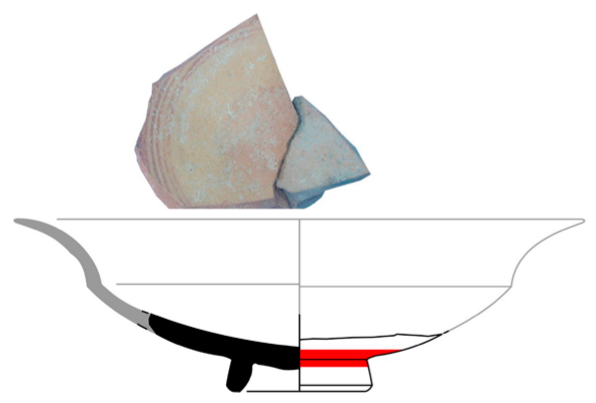

UE 100-5

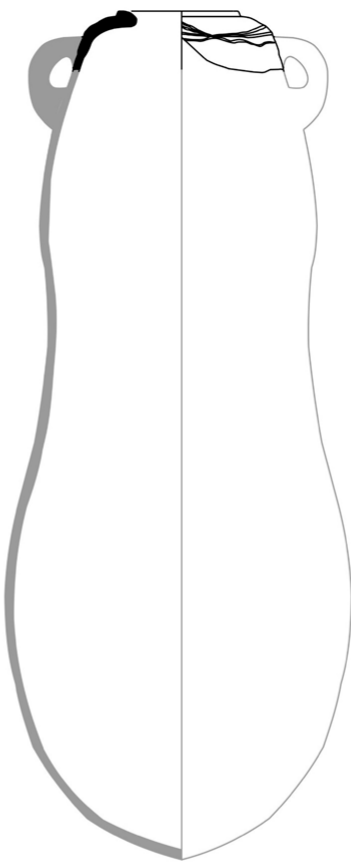

UE 100-15

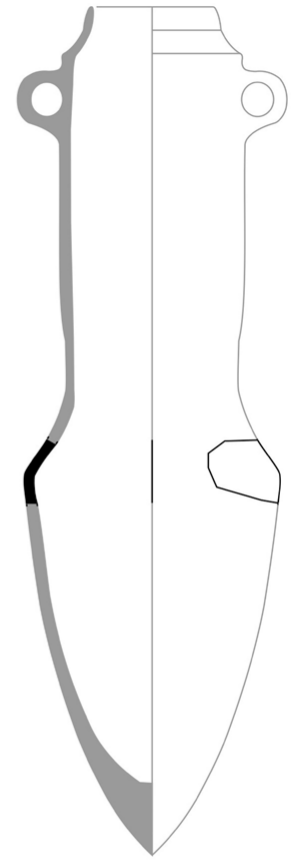

UE 100-19

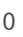

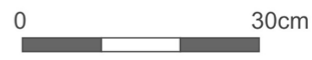

Figura 5: Repertorio material de la UE 100: platos pintados (1 y 5), ánfora contestana (15) y ánfora Tagomago (19).

\section{SÍNTESIS DE LA EXCAVACIÓN ARQUEOLÓ- GICA}

Las zanjas practicadas permitieron localizar restos inmuebles a una profundidad media de 0'70-0'80 m respecto a la cota actual del terreno, con un primer estrato superficial de $55 \mathrm{~cm}$ de espesor (UE 100) de arena de color castaño-gris, bastante suelta y con restos vegetales, homogénea y algo arcillosa. Su retirada, que ya mostraba un elenco cerámico frecuente (Fig. 5), no permitió ver la planta completa del edificio, pero sí buena parte de ella, lo que favoreció la sectorización

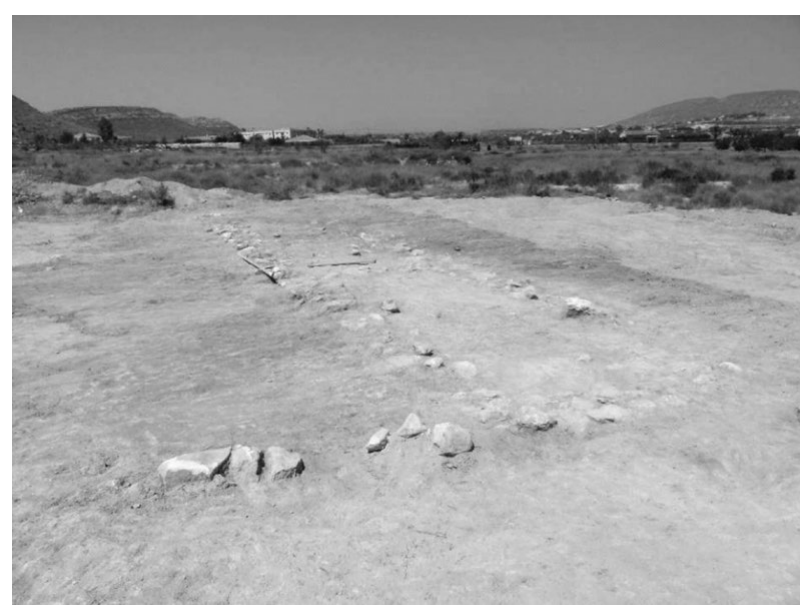

Figura 6: Vista desde el sudeste de la construcción tras retirar la UE 100. del área entre las tierras que quedaban dentro de los habitáculos que iban definiéndose y las que se extendían fuera (Fig. 6).

Por debajo de la UE 100 aparece un estrato de unos $15 \mathrm{~cm}$ de grosor de arena de color más claro, algo más compacta y arcillosa que la unidad citada. Dicha capa de tierra, numerada con un dígito particular según el departamento, descansaba en muchos puntos sobre el sustrato natural -una arcilla anaranjada estéril-; en otros se apoyaba o cubría las estructuras y los estratos de uso grisáceos que veremos a continuación.

A continuación de numerar las nuevas unidades estratigráficas de la planta resultante, se trazaron dos secciones volantes cruzadas en ángulo recto: la A-A' se estableció a $1 \mathrm{~m}$ al norte del paramento interior de lo que sería el muro UE 1001, que cierra la construcción por el sur, mientras B-B' se situó igualmente a 1 $\mathrm{m}$ del paramento occidental del muro UE 1004, que servía de medianera entre los ambientes 2 y 3 .

A estas alturas ya se adivinaba una modesta construcción de mampostería, ya por entonces de dudosa interpretación, pues, además, el material superficial no ofrecía ni excesiva variedad ni vajilla importada. Su cronología tendía a centrarse en la fase plena de la cultura ibérica, hacia los siglos IV-III aC, pues algunas piezas superficiales, como los fragmentos de ánforas acanaladas ebusitanas o de las denominadas ánforas contestanas -con el típico escobillado impreso en sus hombros-, o incluso un fragmento de borde moldurado de kalathos pintado, serían más propias de este horizonte temporal. 
Conviene anotar desde el principio que la UE 100 incluye casi el $60 \%$ del total de fragmentos cerámicos localizados -en concreto, el 58,5\%-, lo que puede interpretarse como una evidencia del alto grado de alteración que han sufrido los restos debido probablemente a la actividad agrícola. Entre el repertorio cerámico hallado, partiendo del número total de fragmentos y obviando los fragmentos de piezas modernas o contemporáneas, así como el sorprendente hallazgo de una moneda italiana de principios del siglo $\mathrm{XX}^{5}$, ya toma cuerpo la caracterización tipológica que va a presentar el asentamiento (Fig. 7): el $71 \%$ de los fragmentos se incluyen en el grupo funcional almacenamientotransporte, casi todos fragmentos anfóricos ${ }^{6}$, además de algunas tinajas y lebetes, tanto pintados como sin decorar; el $28 \%$ se corresponde con formas propias de la vajilla de mesa -destacando los platos, pintados o no-, quedando el $1 \%$ restante para las ollas de cocina de cocción reductora. Esta estadística preliminar ya resulta reveladora de la funcionalidad del lugar, siendo su identificación como área de almacenaje la propuesta que más debe acercarse a ésta.

Es igualmente interesante valorar otros restos aparecidos en esta unidad, como el fragmento de un molino barquiforme o la testimonial presencia de fauna ${ }^{7}$. La ausencia de esta última indicaría la escasa existencia de prácticas de consumo de carne en el asentamiento, amén de imposibilitar su relación con prácticas ganaderas, mientras que la aparición del molino evidenciaría la realización de tareas de moltura (¿cereales, frutos...?), dato de gran valor cualitativo a propósito de la funcionalidad del hábitat.

Levantado este estrato superficial y a la vista de los tres ambientes que ya se adivinaban en la planta de un edificio rectangular, se procedió a retirar las tierras que aún cubrían la construcción, siguiendo ya una enumeración sectorial: UUEE 101/111, 121 y 130, para el interior de los ambientes 1,2 y 3 , todas ellas equivalentes. Se trata de ese conjunto de arenas más claras que aparecen por debajo de la UE 100 y tras cuya excavación se pudo definir por completo la planta del conjunto (Fig. 8).

La construcción documentada presenta una alargada planta rectangular con unas medidas máximas de $17^{\prime} 75 \times$ x 3'10 $\mathrm{m}\left(55 \mathrm{~m}^{2}\right)$, teniendo su eje mayor orientado grosso modo de este a oeste y repartido éste en tres ambientes consecutivos en los que se subdivide

\footnotetext{
5. Una moneda acuñada entre 1903-1908 perteneciente al reinado de Víctor Manuel III, un valor de cobre emitido por Filippo Speranza de $20 \mathrm{~mm}$ de diámetro y 2 gr de peso.

6. Entre ellos se encuentra un fragmento de carena de un ánfora púnica tipo A4 o T-11.2.1.3 de la tipología de J. Ramón (1995), más conocida como ánfora Tagomago, un buen referente cronológico para el contexto ibérico que analizamos.

7. Incluso el único fragmento de hueso hallado más parece un objeto de adorno o colgante -una astilla ennegrecida perforada con un agujero en uno de sus extremos- que resto de un potencial consumo.
}

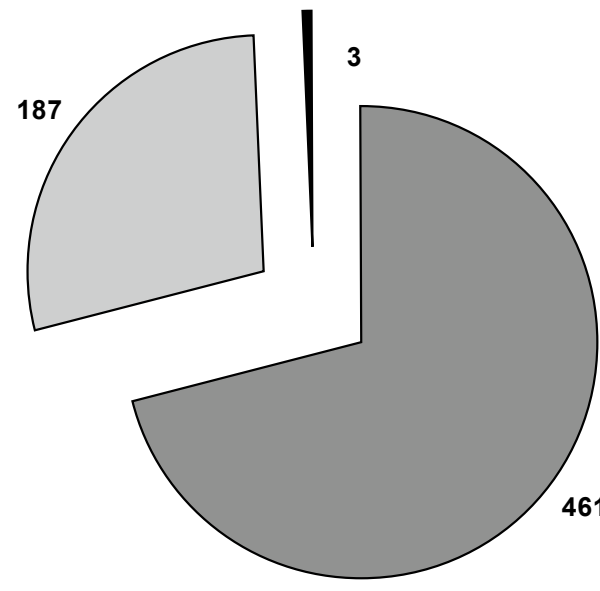

\section{$\square$ Alm-Trans $\square$ Mesa $\square$ Cocina}

Figura 7: Materiales cerámicos de la UE 100

el interior. Además, se documentaron los restos de un murete a modo de apéndice que se proyecta hacia el sur desde la esquina suroriental del conjunto y, por último, se halló otro muro aislado al sur de la construcción, orientado de este a oeste y situado a unos 3' $5 \mathrm{~m}$ al sur de la fachada meridional del edificio. Resulta tentador relaciona estas dos últimas estructuras con la existencia de una tapia que delimitara un gran espacio abierto por este flanco.

Los restos constructivos están muy arrasados, estando la mayor parte de su planta conformada por una única hilada de mampuestos, siendo excepcional la segunda. Además, el sector occidental -básicamente el ambiente 1- se encuentra altamente perdido, y apenas se puede seguir el trazado de sus muros, así como su cierre occidental, que parece, no obstante, bien situado gracias al hallazgo in situ de dos mampuestos de calibre grande, alineados y perpendiculares a los cierres norte y sur. La planta obtenida resulta bastante coherente si comparamos sus medidas teóricas con las obtenidas en los departamentos 2 y 3, como veremos más adelante. Sería, por tanto, un edificio de planta rectangular tripartito, conformando, mediante tabiques interiores que se adosan a los muros maestros que delimitan la construcción, tres estancias de medidas similares. Resulta obvio que se ha pretendido, aunque sin lograrlo con exactitud, establecer tres habitaciones más o menos iguales, quizás por la similitud de funciones que iban a acoger.

Por otro lado, la escasa altura que presentan los muros provoca una merma de documentación en lo que se refiere a los vanos de acceso a cada habitación. No ha sido localizado ningún umbral, por lo que es lógico pensar que éstos se encontraban a partir de la primera hilada conservada del edificio -siendo así, es posible que alguna de las piedras dibujadas hiciera las veces de umbral- $\mathrm{o}$, menos probable, a partir de la segunda. Como quiera que tampoco se han localizado 

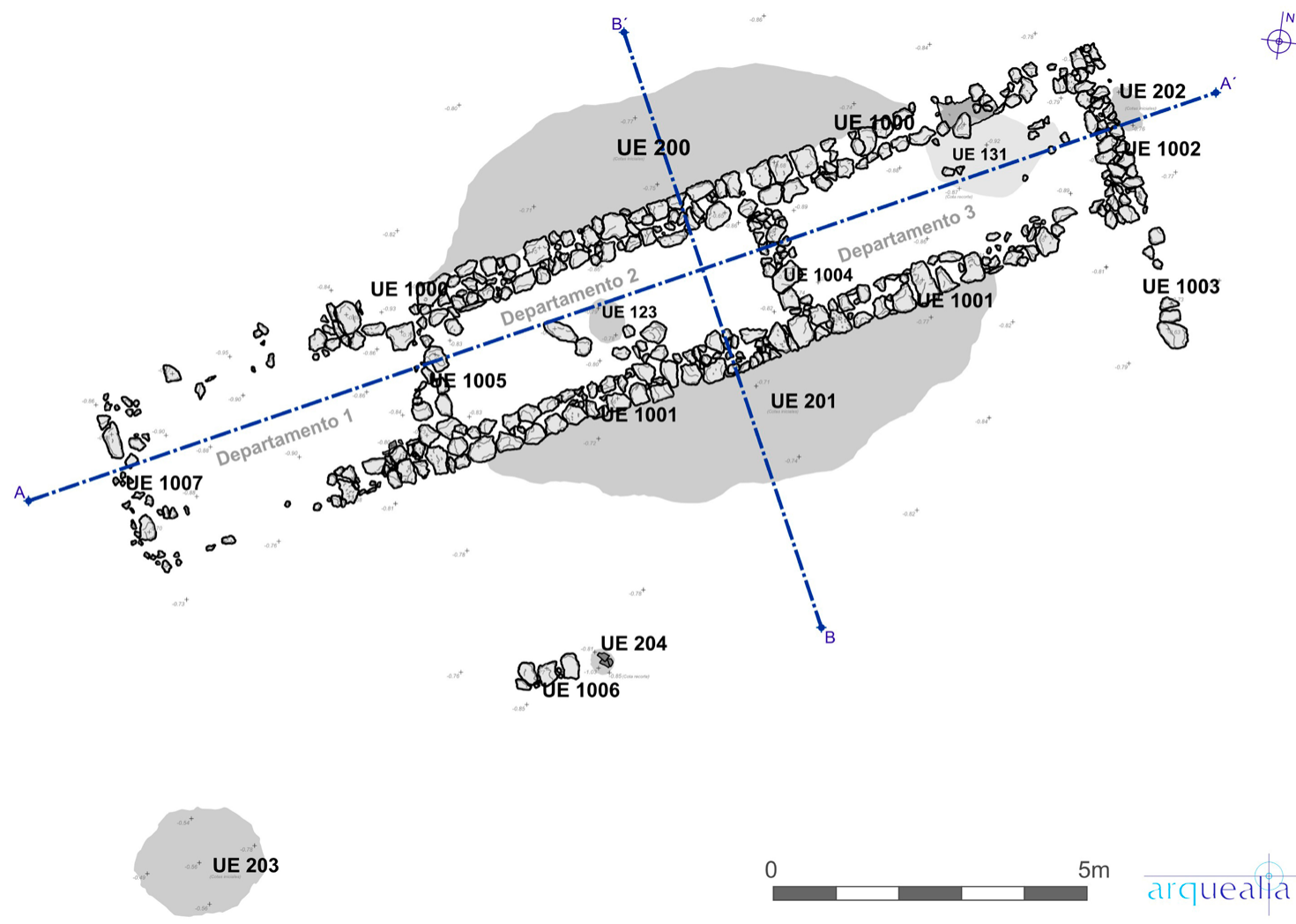

Figura 8: Planta de los restos exhumados.

pavimentos en el interior de las estancias, resulta muy difícil situar sus vanos de acceso y conocer si se intercomunicaban, aunque la acumulación de tierras grises al exterior nos permitirán plantear una hipótesis sobre la ubicación de las puertas y cómo pudieron ser sus umbrales.

Finalmente y en cuanto a estas últimas, en los alrededores inmediatos a la construcción -de hecho, apoyan contra ella- aparecen amplias extensiones de arenas grisáceas, con trazas de cal y algunos carboncillos; contienen una buena cantidad de material cerámico y muestran una sedimentación propia de la ocupación del edificio o, mejor, de su exterior inmediato, pues no se documentan en el interior de las estancias. Estas unidades se numeran como UUEE 200 y 201 para las situadas respectivamente al norte y al sur de la estancia 2, UE 202 para la localizada junto a la pared oriental del ambiente 3 y UE 203 para una última concentración que aparecía a unos $4 \mathrm{~m}$ al sudoeste de la esquina suroccidental del $\mathrm{n}^{\mathrm{o}} 1$.

\section{LA ESTRATIGRAFÍA DEL YACIMIENTO}

La sencillez de la sección longitudinal obtenida del conjunto excavado (Fig. 9) da cuenta de una secuencia estratigráfica simple, tabular y homogénea, probable indicio de una escasa duración de su ocupación o, al menos, de un uso poco intensivo de las instalaciones. A ello habría que añadir la inexistencia de equipamientos tales como revestimientos parietales o huellas de suelos, o el limitado registro material hallado, sobre todo, en el interior de las estancias. Partiendo de este punto, las estancias identificadas se numeran como departamentos 1,2 y 3 , siguiendo una ordenación de oeste a este, mientras las tierras grises exteriores han sido registradas, según su ubicación topográfica, bajo los epígrafes Área Norte, Este, Sur y Sudoeste.

\section{DePARTAMENTO 1}

Alterado en su mitad occidental, posiblemente por la acción del arado y la construcción de un inmediato bancal, ha perdido buena parte de los muros norte (UE 1000) y sur (UE 1001), ambos ejes axiales de la construcción que comparte con las otras dos estancias; el oriental (UE 1005) está casi completo y del occidental (UE 1007) quedan, como ya señalamos, dos bloques grandes alineados que, sin duda, parecen pertenecer a la planimetría original. Con ello se obtiene un habitáculo de unos 4'60 x 1'65 m, esto es, casi $8 \mathrm{~m}^{2}$ de espacio construido.

Bajo la UE 100 aparecen los ya citados estratos 101 y 111, equivalentes pero sin contacto físico. Deben adscribirse a los niveles de destrucción y ofrecen un registro cerámico monótono y poco abundante (Fig. 10), que, no obstante, nos permite valorar con precisión, siguiendo el criterio de NMI, el conjunto obtenido. De la UE 101 procede un borde de ánfora y 

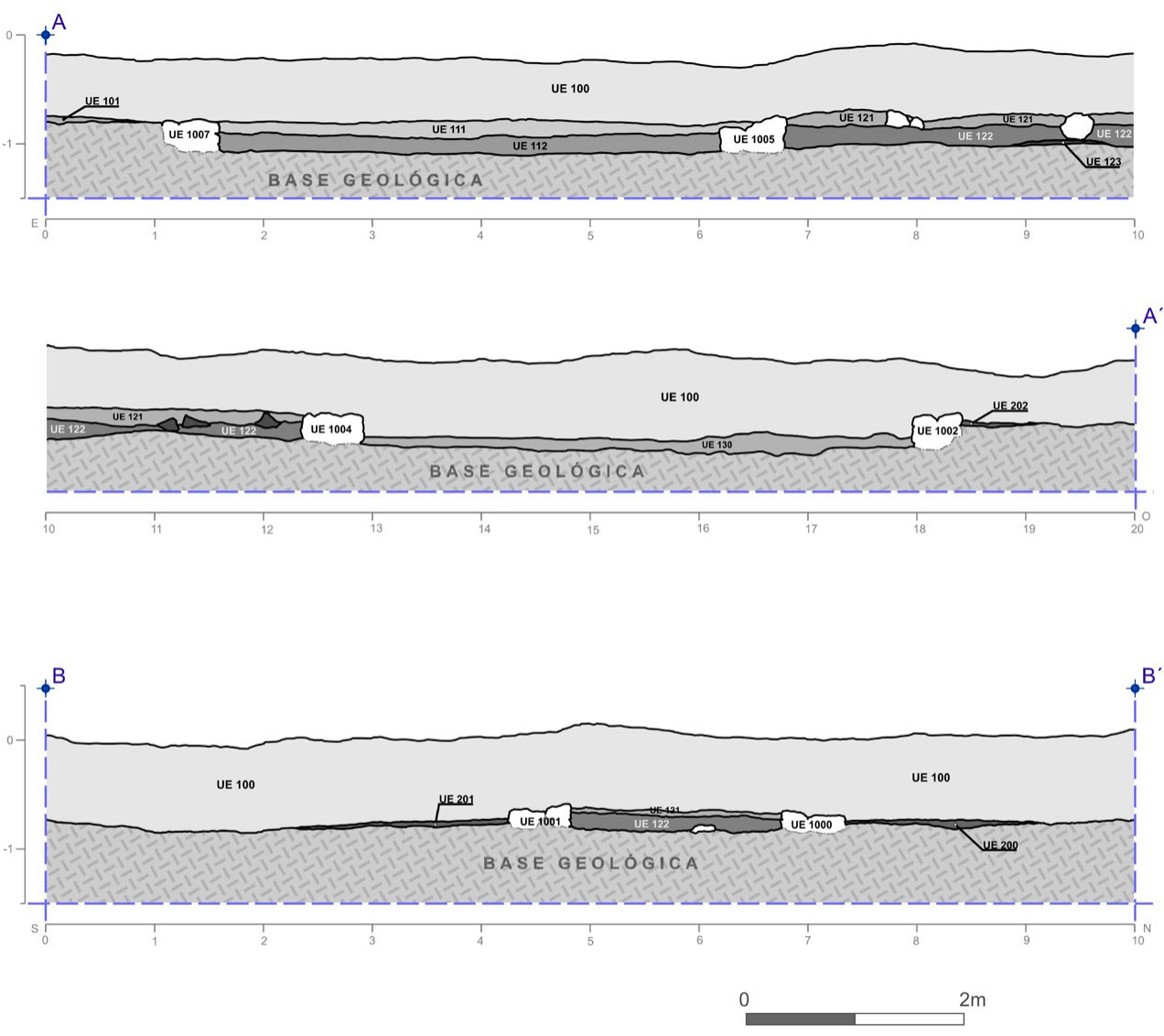

arquealia

Figura 9: Secciones A-A’ y B-B'.
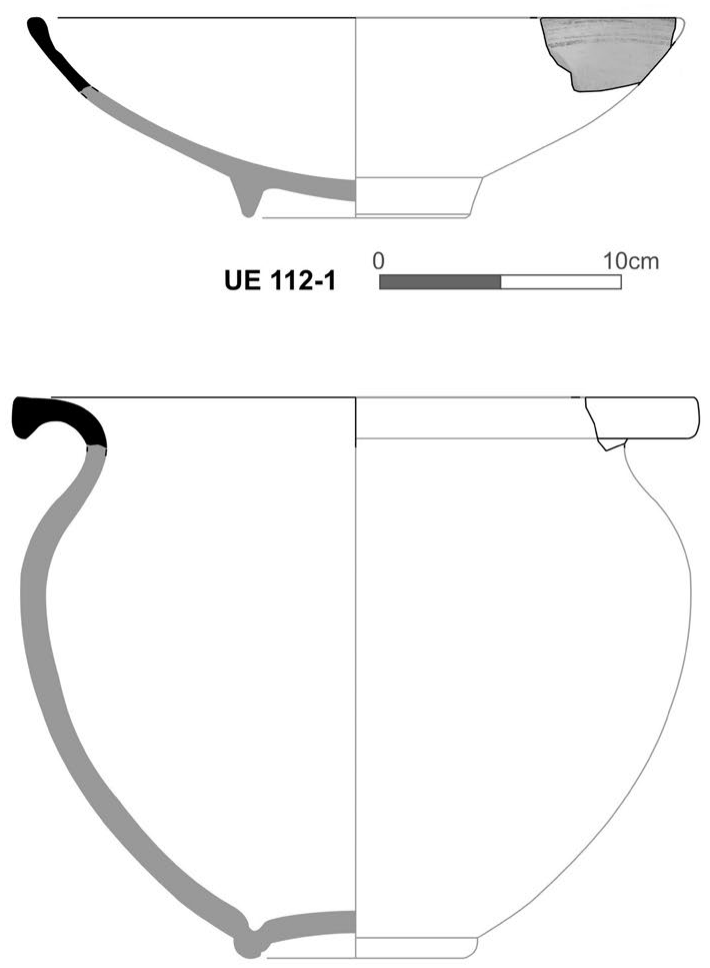

UE 112-4 $10 \mathrm{~cm}$

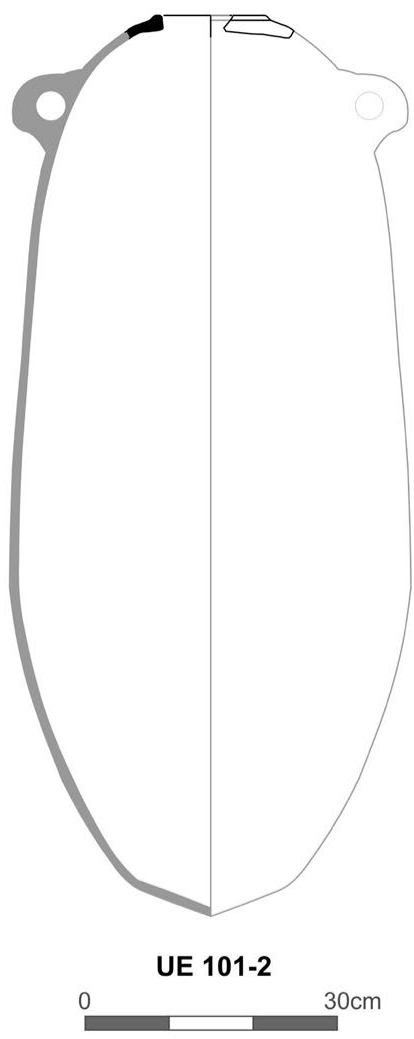

Figura 10: Repertorio material del Dpto. 1: platos pintado (112-1), olla de cocina (112-4) y ánfora local (101-2). 
el asa de un posible oenochoe pintado, además de una barca de sepia; en la 111 aparecen fragmentos informes de los mismos tipos.

Por debajo de ambas se detecta una última capa de tono castaño claro, arenosa y homogénea, compacta y con trazas calizas (UE 112); alcanza 6-8 cm de espesor, llegando a la cota de apoyo de los muros y estando bien delimitada por estos, por lo que se correspondería con el nivel de ocupación. Ha proporcionado un repertorio cerámico aceptable: 86 fragmentos anfóricos, 27 comunes, 5 pintados y 3 de cocción reductora. Los porcentajes sobre el total serían del $71 \%$ para ánforas -incluyendo un ejemplar con escobillado en el hombro, que N. Álvarez identifica como típico de las ánforas contestanas (Álvarez, 1997)-, $22 \%$ de cerámicas comunes no decoradas, $4 \%$ para las pintadas -siempre con temática geométrica y tono rojo vinoso-, y $3 \%$ de cerámica de cocina. Si acudimos al concepto de NMI, los cálculos varían un tanto, pues se contabilizarían dos bordes de ánfora, dos de platos pintados, uno de olla de cocina y otro fragmento recortado con forma circular, conocido como tejuelo y que bien podría haber servido como tapón. El ajuar doméstico mostraría,

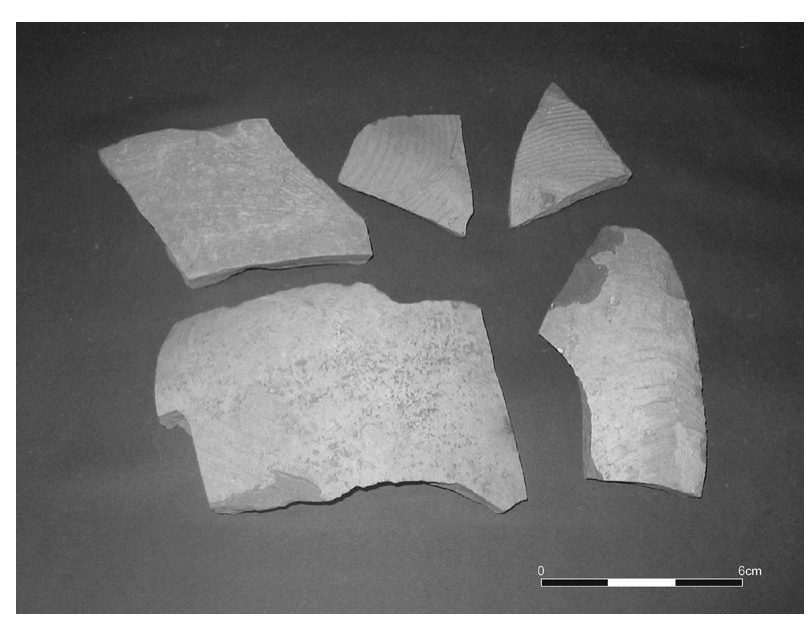

Figura 11: Materiales anfóricos del Dpto. 2; arriba, fragmentos escobillados.

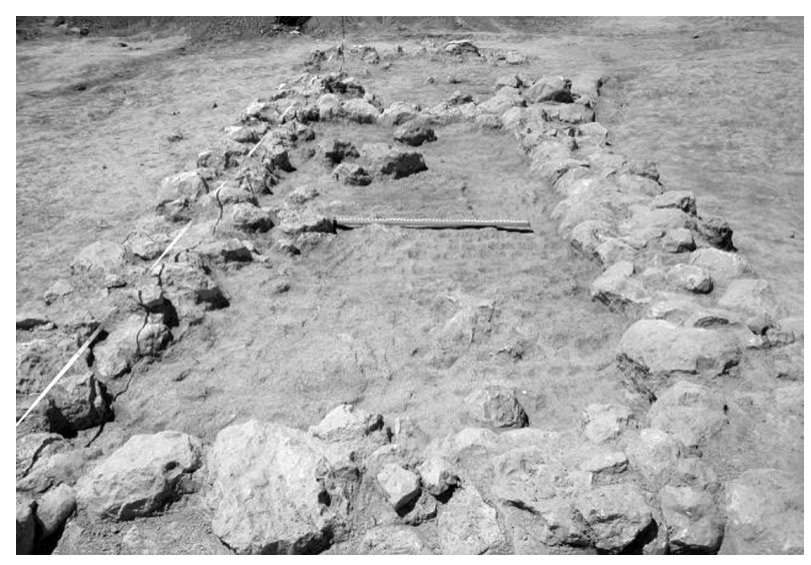

Figura 12: Vista desde el este del Dpto. 2; hacia el centro la UE 123. así, recipientes de almacenamiento y transporte, vajilla de mesa y una olla para poner al fuego; parece, por tanto, que estamos ante una estancia polifuncional en la que se realizarían distintas actividades, con cierta preponderancia de la función de almacenamiento/ transporte.

\section{DEPARTAMENTO 2}

El mejor definido, conserva por completo los fundamentos de los muros que lo delimitan: comparte con la estancia 1 el septentrional, el meridional y el occidental (UUEE 1000, 1001 y 1005), mientras por el este se define un nuevo de muro de separación con la $\mathrm{n}^{\circ} 3$ (UE 1004). Dibujan un rectángulo de 5'56 x 1'92 $\mathrm{m}$., casi $11 \mathrm{~m}^{2}$, siendo, en consecuencia, el de mayores dimensiones del edificio.

Su estratigrafía remite a la estancia 1 , con un primer estrato (UE 121) de similar morfología a la unidad 111 , algo más grueso $-12-16 \mathrm{~cm}-$, al que sigue una capa (UE 122) igualmente equivalente a la UE 112, con presencia de varios mampuestos caídos. De estas unidades proceden 68 fragmentos cerámicos (Fig. 11), repartidos entre 59 de ánforas ibéricas -dos con escobillado-, 3 de origen púnico-ebusitano -identificados por sus paredes acanaladas, amén de la diferencia de pasta cerámica-, 5 fragmentos pintados y otro de cocina. Siguiendo un cómputo propio del NMI, y a pesar de carecer de fragmentos de borde, podemos convenir que hubo al menos un ánfora púnica, una olla de cocina y un recipiente pintado, posiblemente un plato; en cuanto a los fragmentos de ánforas locales, no parece exagerado valorar en, al menos, dos los envases a contabilizar, teniendo en cuenta los dos fragmentos de hombros escobillados. El ajuar no se alejaría demasiado de lo establecido para la estancia 1.

Esta orientación funcional podría matizarse un tanto por el hallazgo de una nueva unidad estratigráfica, pues, por debajo de la unidad 122 , se detecta una huella negruzca de tendencia circular (UE 123), presumiblemente de un hogar, situada hacia el centro de la habitación y de unos $60 \mathrm{~cm}$ de diámetro. A su alrededor aparecen varias piedras de tamaño grande, que tal vez hicieron las veces de cortavientos o como simples asientos. Estaríamos ante la evidencia de un fuego, que pudo servir para satisfacer unas básicas condiciones alimenticias, así como lugar de reunión al amparo del calor, en torno al cual se pudieron desarrollar otras actividades que no han dejado huella arqueológica (Fig. 12).

Es interesante, por otro lado, reflexionar sobre la secuencia de cotas en su interior, pues es una buena pista para calibrar cómo funciona el acceso al departamento. La hoguera 123 aparece a una cota de -0 '77, más o menos al nivel del suelo al exterior del edificio, entendiendo éste como el punto donde apoyan las capas grises, que veremos más adelante; es decir, en el diseño inicial, el suelo de dentro de la estancia está a la 
misma altura que fuera de ella. Teniendo en cuenta que la altura de los muros ronda la cota -0'65, ello implicaría, como hipótesis de partida, un umbral situado en esta primera hilada, de $12 \mathrm{~cm}$ de altura, fácil de salvar; otra solución parece menos ventajosa.

\section{DEPARTAMENTO 3}

Con la misma consistencia constructiva que la anterior, ofrece un pobre registro tanto estratigráfico como material. Compartiendo con el resto del edificio los muros norte y sur (UUEE 1000 y 1001) y con la estancia 2 el occidental (UE 1005), por el este lo cierra la estructura 1002, límite de la habitación y de toda la construcción. Además, en su esquina sudeste se aprecia la existencia de una nueva construcción (UE 1003), que se proyecta hacia el sur 2'64 m, siendo un murete de peor factura que los hasta ahora citados, pues apenas si conserva un paramento de mampostería. Quizás sirviera como soporte de algún tipo de equipamiento, a modo de porche, o incluso como tapia. En definitiva, el tercer habitáculo dibuja una planta parecida a las anteriores, de 5'03 x 1'79 m., lo que suponen $9 \mathrm{~m}^{2}$ de espacio construido, perfectamente equiparable a lo calculado en las dos estancias previas.

Como señalamos, apenas tiene potencia estratigráfica, siendo visible en algunos puntos el substrato rocoso del terreno en cuanto se levanta la capa superficial. En el resto aparece la UE 130, un estrato equivalente a las unidades 111 y 121; su excavación tan sólo ha recuperado 14 fragmentos cerámicos informes, todos ellos de recipientes anfóricos locales, por lo que habría que convenir que su función como lugar de almacenaje parece la más probable.

Por otro lado, tras levantar la unidad 130, se observó, hacia el ángulo nororiental del departamento, un rehundimiento del estrato natural de unos 3-4 cm. de profundidad de planta groseramente circular (UE 131), una huella en negativo de unos $140 \mathrm{~cm}$ de diámetro impresa sobre dicho substrato. Se nos ocurre que dicha huella pudo haber sido originada por la presión ejercida por el peso de algún tipo de artilugio, seguramente de piedra, situado en este punto (Fig. 13). Desconocemos las características y funcionalidad de este hipotético ingenio, pero lo que aparece evidente es que su presencia determinaría sin duda la funcionalidad de la habitación, matizando de nuevo el carácter de lugar de almacenaje que el registro cerámico apuntaría. Hemos manejado la posibilidad de hallarnos ante la huella de un molino rotativo, pues este equipamiento podría llegar a tener $60 \mathrm{~cm}$ de diámetro, alcanzando un metro de medida si consideramos la posibilidad -constatada en varios yacimientos ibéricos (Alonso i Martínez, 1999, 244)-de que dicho artilugio se asentara sobre una plataforma de piedras. La diferencia entre los 90-100 cm de diámetro que tendría este molino y los 140 que muestra la huella impresa es notoria, por lo que habrá que considerar dicha interpretación en el terreno de la hipótesis.

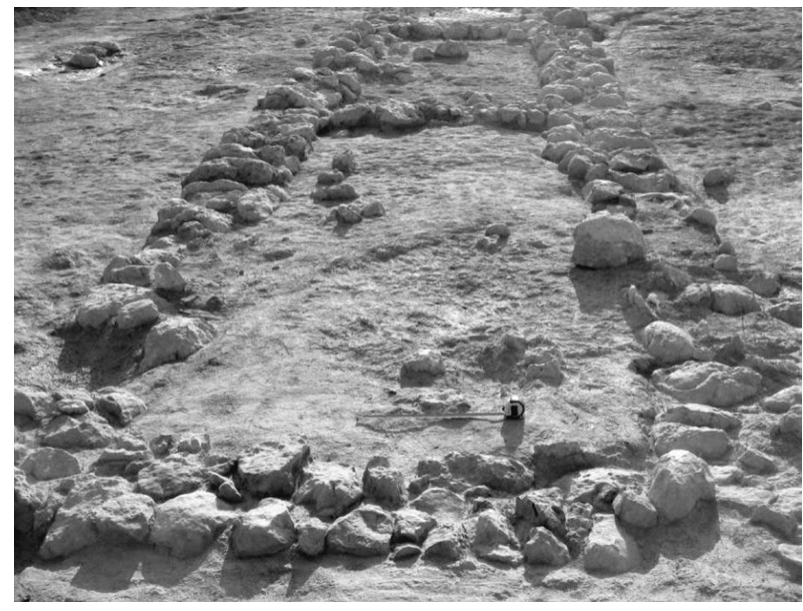

Figura 13: Vista desde el este del Dpto. 3; en primer término la UE 131.

\section{Área NorTe}

El terreno inmediato al exterior del edificio se encuentra parcialmente colmatado por una unidad estratigráfica similar que, si bien, no muestra una total continuidad, por lo que era aconsejable una identificación particular para cada una. Se trata de una arena grisácea, algo arcillosa, homogénea y poco compacta, con trazas de cal, gravas y pequeños carbones, siendo igualmente frecuente la presencia de fragmentos cerámicos. Por debajo de ella ya aparece el estrato natural.

Caben muchas dudas sobre su origen y, de forma genérica, puede considerarse como el registro sedimentario de actividades relacionadas con fuego realizadas al exterior del edificio, pues las estancias no muestran un vestigio similar. Tales unidades presentan un perfil en cuña, apoyándose en los muros de la construcción, para ir progresivamente adelgazando su grosor conforme el estrato se aleja de las fachadas. Ello significaría que los vertidos se iniciarían junto al edificio, alejándose de él de forma paulatina, pasando después, tal vez, a almacenar el producto obtenido, ya «limpio», en las estancias.

La mayor cantidad de sedimento acumulado es la del Área Norte (UE 200), un estrato que en planta adopta una forma triangular, con un eje mayor de unos $8,50 \mathrm{~m}$ apoyado contra el muro 1000 , delante de las estancias 2 y 3 ; se proyecta hacia el norte 1' $80 \mathrm{~m}$, ocupando unos $8 \mathrm{~m}^{2}$, y ofrece un grosor máximo de $7 \mathrm{~cm}$ en el punto de apoyo con el muro.

De esta unidad proceden 94 fragmentos cerámicos -bastantes con huellas de quemado-, lo que da a entender que en el exterior de la construcción se acumula mayor cantidad de registros que en su interior, probablemente por ser estos espacios abiertos las áreas de trabajo. Su reparto, aplicando el NMI, sería: dos ánforas, dos lebetes, cuatro platos - dos de ellos pintados-, una olla de cocina -decorada con líneas incisas en el cuello-y la base de una cazuela (Fig. 14). 


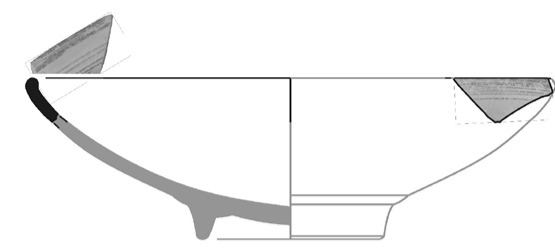

UE 200-1

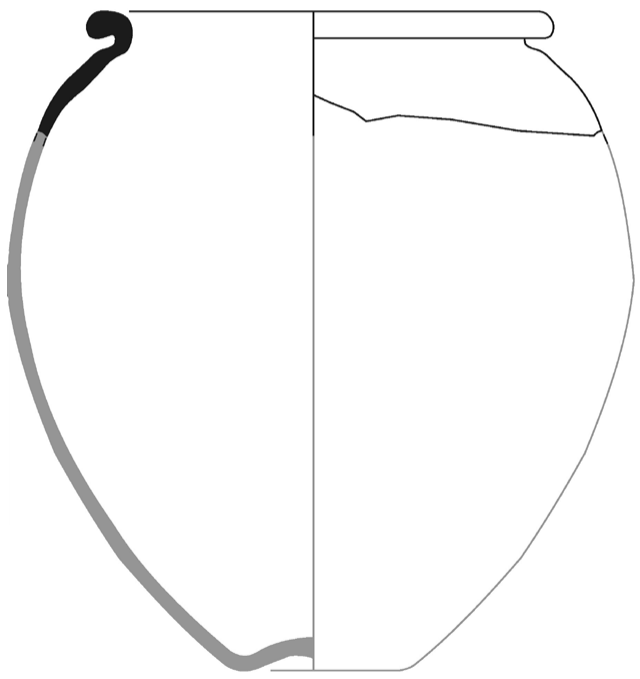

UE 200-8

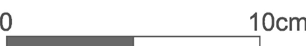

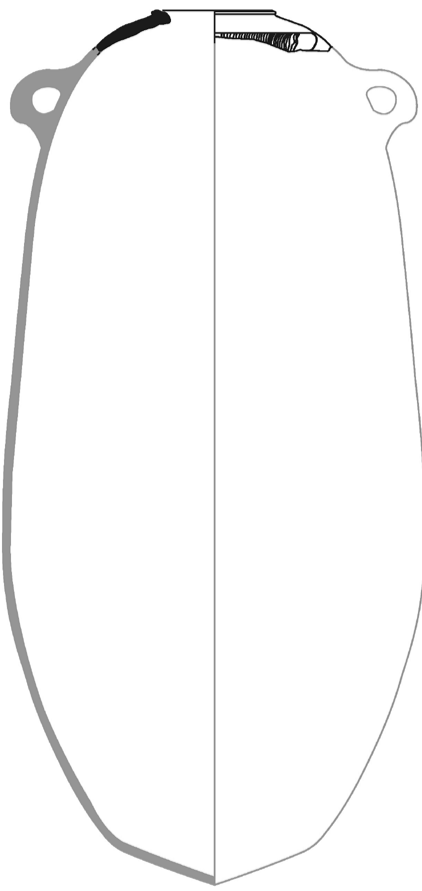

UE 202-3

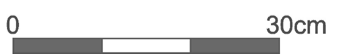

Figura 14: Repertorio material de las UUEE 200 y 202: plato pintado (200-1), olla de cocina (200-8) y ánfora contestana (202-3).

A título de hipótesis, es probable que el proceso productivo que ha generado los vertidos -vinculado permanentemente con fuegos- formara parte de la actividad principal realizada en el lugar, seguramente una fase del mismo, aunque no estamos en condiciones de concretarla. Hemos valorado la posibilidad de estar ante los restos del tostado de cereales, si bien ello choca frontalmente con la absoluta ausencia de restos carpológicos de esta especie vegetal, o de cualquier otra, no sólo en esta unidad, sino en todas las restantes $^{8}$, por lo que seguimos sin poder ofrecer una hipótesis plausible sobre su naturaleza.

\section{Área Este}

Un nuevo manchón se detecta junto al muro oriental de la estancia 3, esta vez de reducidas dimensiones, tal vez por proceder de un único vertido. El estrato grisáceo (UE 202) adopta una forma elíptica alargada

8. Se llevó a cabo el cribado por flotación de un amplio muestreo de estos sedimentos grisáceos, con resultados enteramente negativos. Estamos a la espera de poder realizar las correspondientes analíticas químicas sobre las muestras de sedimento recuperadas. en sentido norte-sur, con unas medidas aproximadas de 0'65 x 0'40 $\mathrm{m}\left(0,26 \mathrm{~m}^{2}\right)$ y un espesor de $2-3 \mathrm{~cm}$.

Sus dimensiones han proporcionado, en coherencia, un parco registro material, tan sólo 25 fragmentos cerámicos: 23 de ánfora local -entre ellos dos bordes y dos informes escobillados-, 1 asa sin decorar y 1 fragmento de pasta gris. Huelga realizar cualquier operación estadística al respecto, aunque no deja de ser sintomático que los tipos reconocidos coincidan con lo observado hasta ahora en casi todas sus unidades.

\section{Área Sur}

Casi en simetría respecto al Área Norte, la UE 201 se apoya a lo largo de $9 \mathrm{~m}$ del recorrido del muro UE 1001, ocupando las fachadas de las estancias 2 y 3 (Fig. 15). Ofrece de nuevo un perfil en cuña, proyectándose hacia el sur 1'96 m. Se trata de la mancha más extensa (17’6 $\mathrm{m}^{2}$ ), no obstante, tiene un menor grosor en su punto de apoyo en el muro -apenas $4 \mathrm{~cm}-$, por lo que, a efectos de volumen de tierra, es menor que la unidad $200^{\circ}$.

9. Hemos realizado un cálculo sobre la tierra acumulada en ambas fachadas, considerando las UUEE 200 y 201 como figuras geométricas. Procesados los datos, la unidad 200 equivaldría a 5351 , mientras que la 201 descendería hasta los 3531. 


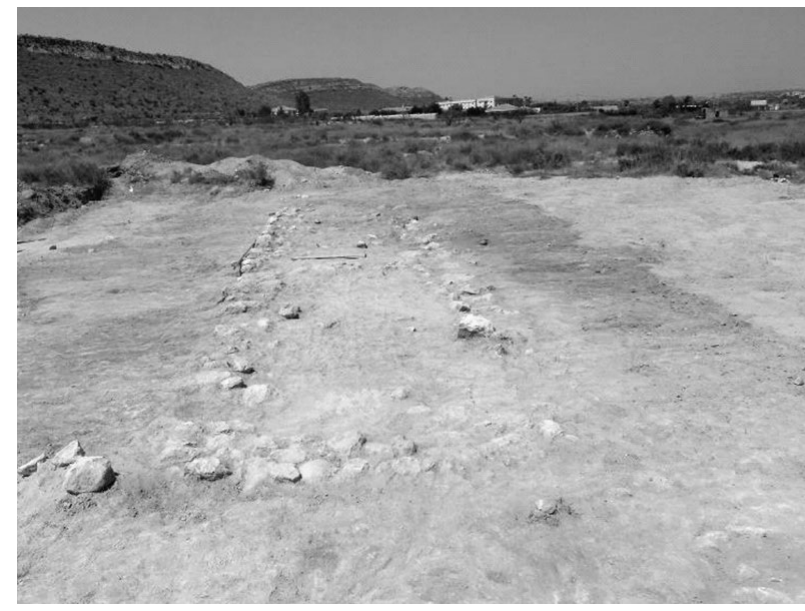

Figura 15: Vista desde el este de las UUEE 200 y 202.

De esta unidad proceden 93 fragmentos cerámicos. De calcular el NMI, se produciría una paradoja, pues no se documenta ningún borde de ánfora, mientras que sí aparecen tres de plato -dos pintados y un tercero sin decorar- y otro de oinochoe, aparentemente sin decorar. Resulta obvio que junto a estas formas habría que considerar la presencia de 2-3 ánforas, una púnicoebusitana. En cualquier caso, vuelven a documentarse unos datos muy coherentes y homogéneos con respecto a las restantes unidades excavadas.

Una última cuestión a considerar sobre este área meridional hace referencia al hallazgo de una última estructura de piedra localizada en la misma. Dispuesto en paralelo al cierre meridional 1001 y a 3'5 m al sur, aparecen los restos de un muro de mampostería (UE 1006), de poco más de un metro de longitud y una única hilada de piedras como paramento. Se encuentra por completo aislado, teniendo por singularidad un recorte groseramente circular realizado en el estrato natural (UE 204), de unos $40 \mathrm{~cm}$ de diámetro y 16-18 de profundidad, que remata la construcción por su extremo oriental. En tal agujero, en su relleno (UE 205), se hallaron tres grandes fragmentos, sin duda in situ, de un ánfora, envase que, al parecer, ocupaba originalmente el recorte, siendo su funcionalidad desconocida. Tampoco tenemos una explicación convincente para la estructura; quizás definiera una construcción tipo tapia que delimitaba un espacio abierto al sur del edificio a modo de patio -junto con la estructura 1003, ambos de similar fábrica-, en donde se realizaran distintas actividades, pero, en cualquier caso, sorprende el remate del muro con un recorte para alojar un ánfora, pues eliminaría desde este punto su función constructiva.

\section{Área Sudoeste}

Finalmente, a unos $4 \mathrm{~m}$ al sudoeste de la esquina suroccidental de la estancia 1 se localiza la última mancha grisácea (UE 203), la cual presenta algunas diferencias respecto a las ya referidas, pues, en este caso, parece

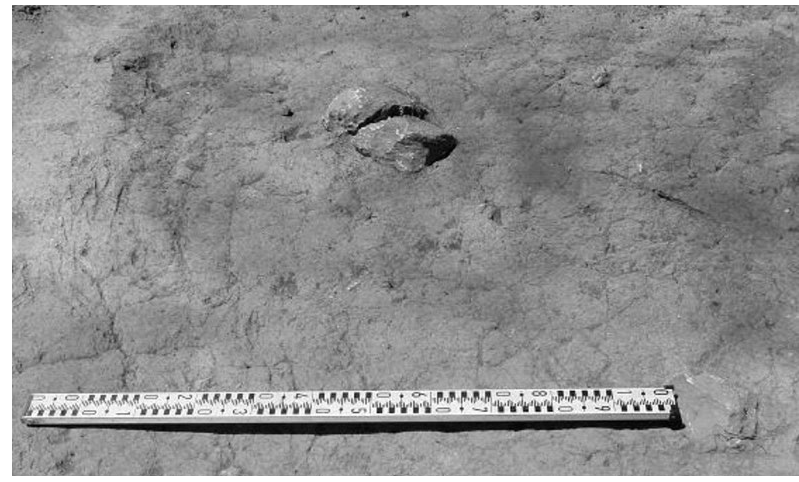

Figura 16: Vista desde el este de la UE 203 una vez excavada.

obvio que estamos ante una zona donde se han realizado hogueras directamente sobre el terreno natural.

Tras retirar las unidades superficiales, se alcanza una capa negruzca UE 203, en la que se advierten huellas claras de rubefacción tanto en las piedras que existen hacia el centro de la mancha -dos mampuestos aislados- como en las tierras del substrato natural que la rodean, que toman una característica y progresiva coloración negruzca-rojiza (Fig. 16). El estrato 203 definiría, así, una última hoguera, una combustión de forma ovalada de unos $2 \mathrm{~m}$ en sentido este-oeste por 1'80 m de norte a sur, quedando la zona central ocupada por los dos mampuestos referidos; una vez excavadas, dejan aflorar, sin más, el substrato natural. De esta unidad proceden apenas 8 fragmentos cerámicos, cinco de ollas de cocina y 3 de ánforas, muy probablemente relacionados con la actividad llevada a cabo en dicha zona.

\section{LA ARQUITECTURA DEL EDIFICIO}

Los restos constructivos exhumados en la excavación ofrecen la imagen de una construcción única que busca la regularidad de la planta rectangular (Fig. 17), aunque ello no se consigue por completo, por distintos motivos. Si bien hay que admitir la casi idéntica

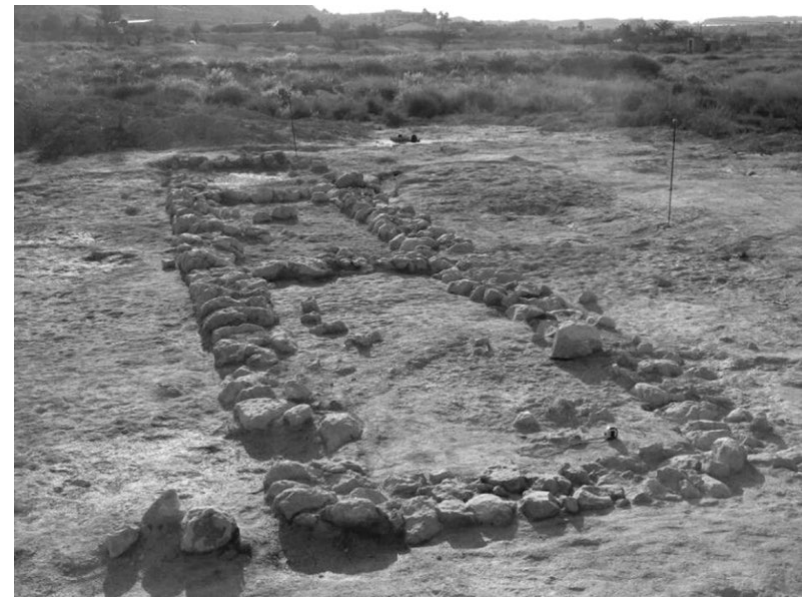

Figura 17: Vista final desde el este de la construcción. 
longitud entre sus fachadas norte y sur -la primera de $17^{\prime} 02 \mathrm{~m}$, por $17^{\prime} 30 \mathrm{~m}$ de la segunda-, los diferentes calibres de estos mismos muros -el grosor varía desde un máximo de 0'78 $\mathrm{m}$ a un mínimo de 0'52-y, sobre todo, la falta de disposición en paralelo de estos ejes axiales -lo que provoca distintas medidas para los muros perpendiculares-, genera una cierta irregularidad en el trazado, que aboga por una construcción bien diseñada pero desigualmente ejecutada, seguramente por ser levantada por individuos con conocimientos básicos en el arte de la construcción.

Ello podría considerarse como un factor a favor de una rápida planificación y ejecución de la obra, sin embargo, la tendencia a la regularidad que busca el diseño del edificio - una construcción alargada subdividida en tres ambientes similares- indica, sin duda, un conocimiento previo sobre plantas arquitectónicas de parecida naturaleza, que deben estar imitando, aunque, insistimos, estos albañiles ocasionales no parecen manejar con fluidez conceptos básicos de arquitectura. Es muy probable, igualmente, que la construcción tuviera un fin específico de carácter agropecuario, que no implicaba un uso continuado y regular, de ahí el escaso esmero de su acabado -como la falta de enlucidos o pavimentos-. En suma, y a pesar de la escasa secuencia estratigráfica conservada, parece ser una construcción realizada posiblemente en mampostería, pues no se ha hallado evidencia alguna de tapial o adobes, siendo más que seguro que, dada la estrechez de la crujía, la cubrición se resolviera mediante un tejado a un agua, posiblemente con una leve inclinación en sentido sur-norte.

El cuerpo de fábrica del edificio se define a partir de dos largos muros que conforman las fachadas norte y sur (UUEE 1000 y 1001). Su orientación se ha calculado en $310^{\circ}$ Este-Noroeste, resolviéndose el cierre por el este intestando ambos con un tercer muro (UE 1002), que muestra una orientación de $60^{\circ}$ Sur-Nordeste; hemos de suponer que por el oeste el muro UE 1007 se levantarían siguiendo la misma pauta. Estas estructuras presentan una fábrica de mampostería no trabajada y dispuesta de manera un tanto anárquica, pues a pesar de que predomina el doble paramento de piedras grandes y medianas con un ocasional relleno intermedio de guijarros, a veces esta disposición es sustituida por una gran piedra dispuesta a tizón, lo que provoca las diferencias de calibre antes reseñadas. En cualquier caso, la anchura media de los muros $1000 \mathrm{y}$ 1001 tiende a los $65 \mathrm{~cm}$-algo más elevada para el primero, $68 \mathrm{~cm}$, respecto al segundo, 64-, mientras que el muro 1002 ofrece un grosor claramente inferior -52 $\mathrm{cm}-$, por lo que parece muy posible que estén modulando a partir de un codo de $52-54 \mathrm{~cm}$, una conocida métrica de origen feno-púnico ${ }^{10}$.

10. El apunte lo debemos al Dr. I. Grau, a quien agradecemos en lo que vale la lectura del texto y las sugerencias planteadas, que sin duda han enriquecido la reflexión que genera el asentamiento.
Las piedras que conforman los muros, que descansan directamente sobre el substrato natural sin cimentación alguna, proceden de la propia formación caliza de la sierra, siendo éstas, como se ha señalado, de calibre muy variado, de lo que se infiere una muy escasa selección del material constructivo. En los pocos puntos donde se ha detectado una segunda hilada, parece adivinarse la búsqueda de cierta regularidad en su disposición, estando todas ellas trabadas con un barro castaño claro, muy homogéneo y duro, sin que se perciban, a simple vista, trazas de otros materiales en la argamasa.

Buscando una evidente axialidad para todo el edificio, se disponen en perpendicular a los muros 1000 y 1001 los tabiques interiores (UUEE 1004 y 1005), que subdividen el espacio interior en tres ambientes. La estructura 1004 es la mejor conservada, dispuesta en paralelo a 1002 y definiendo así el ambiente 3, con 1'79 m de luz. Dicho muro se apoya con nitidez en 1000 y 1001, pero la inexistencia de pavimento o niveles de uso impide precisar el instante concreto de su construcción; el hecho de que su hilada descanse a una cota idéntica respecto a las estructuras citadas, orienta a una construcción inmediatamente después de éstas, por lo que la subdivisión interior tenía que estar presente en la planificación original. A efectos constructivos, la técnica y trabazón es similar a la ya descrita, si bien los mampuestos son de un calibre menor, por lo que su anchura media se reduce hasta $\operatorname{los} 58 \mathrm{~cm}$.

En cuanto al tabique 1005, ofrece una fábrica idéntica a la descrita para 1004, si acaso algo más ancha $-62 \mathrm{~cm}-$, e igualmente se apoya contra los muros 1000 y 1001, manteniendo la misma relación de cota descrita más arriba. Las estructuras 1004 y 1005 delimitan la estancia central del conjunto, el ambiente 2 , que resulta ser el de mayor superficie construida, casi $11 \mathrm{~m}^{2}$, diferencia que tampoco parece exagerada, pues sólo sería un $18 \%$ más grande que el $\mathrm{n}^{\circ} 3$.

Por último, la estructura 1005 sirve también para delimitar la estancia 1, a la que ya hemos aludido como la peor conservada. Los restos del cierre occidental (UE 1007), apenas dos bloques con un calibre de muro calculado de $59 \mathrm{~cm}$, permiten no obstante reconstruir los límites de una habitación de 7' $6 \mathrm{~m}^{2}$, resultando ser la de menor tamaño del conjunto; en cualquier caso y una vez más, no es una superficie alejada de la media de los tres habitáculos, situada en 9' $1 \mathrm{~m}^{2}$.

Una cuestión que ha quedado por dilucidar es la referente a la localización de los umbrales de acceso a las habitaciones, existiendo la doble posibilidad de considerar bien entradas independientes a cada habitáculo, bien a través de un acceso principal que condujera hacia una circulación interior por las tres estancias. Los restos no permiten localizar con precisión la ubicación de dichos umbrales: no se observa interrupción alguna de la hilada conservada, ni ningún preparado de argamasa singular, ni una disposición ordenada de algunos mampuestos -por ejemplo, las piedras colocadas a tizón-, ni tampoco existen pavimentos, por 
lo que no se puede intuir una relación constructiva especial tendente a ubicar el umbral en un punto determinado. En cualquier caso, como ya indicamos, la comparación de cotas entre el interior de la estancia 2 y la cota de apoyo de los estratos grises, similar en ambos casos, permite inferir que es probable que los umbrales del edificio estén contenidos en la primera hilada levantada, pues una segunda hilada ya se antoja un escalón de hasta $30 \mathrm{~cm}$ de altura, demasiado incómodo para el trasiego de recipientes y productos.

Por otro lado, la dispersión de los sedimentos grisáceos que aparecen al norte y al sur de la construcción podrían suponer un buen indicio respecto a la ubicación de los vanos de las estancias, pues su localización y espesor indicarían un lugar de vertido principal junto al edificio, con una progresiva delgadez de estos conforme se alejan de ese origen. Ello se documenta en las dos fachadas y suponemos que los vanos esquivarían los puntos de vertido - pues nada de ellos penetra en el interior-, situándose teóricamente a sus lados, excéntricos. En conclusión, la hipótesis que manejamos es considerar como posible la existencia de un umbral en la fachada norte de la estancia 2 y otro en su fachada sur, es decir, dos accesos enfrentados, que, a su vez, y aquí caminamos ya por la conjetura, permitirían acceder a las estancias 1 y 3 a través de los muros 1005 y 1004. Los mayores indicios de actividad y el mayor tamaño de esta estancia central abundarían en esta dirección, siendo así la habitación principal a cuyos lados se abrirían espacios anexos relacionados con las tareas efectuadas en aquélla.

Finalmente, quedarían por interpretar los dos muretes situados junto a la fachada sur del edificio. El primero de ellos (UE 1003) es una proyección hacia el sur del muro oriental de la construcción (UE 1002), al que claramente se adosa. La línea de la estructura se sigue 2'64 m, recorrido definido por un único paramento de mampostería de calibre grande y mediano. Resulta difícil calcular su anchura original, pero dado el tamaño del bloque que marca el final del tramo conservado, el grosor podría rondar los $40 \mathrm{~cm}$. Este reducido espesor, junto a su estado de conservación, redundaría en la hipótesis de definirlo como elemento delimitador, para el que no se prevé una excesiva carga constructiva. La segunda construcción (UE 1006) se encuentra ya fuera de los límites del edificio, en paralelo al muro meridional del mismo. Se trata de una estructura que conserva tres grandes bloques de piedra colocados a tizón, acompañados por varios guijarros situados entre ellos y una postrera piedra mediana que remata la construcción por el oeste. Se define así un muro de 1'06 m de longitud por 0'42 de calibre, como 1003. Por el este puede defenderse la localización de su extremo, pues, inmediatamente a continuación del último mampuesto, aparece un recorte del terreno natural (UE 204) en cuyo relleno (UE 205) se localizaron varios fragmentos de un ánfora. Su funcionalidad resulta, por el momento, desconocida, pero, en cualquier caso, parece evidente que la construcción 1006

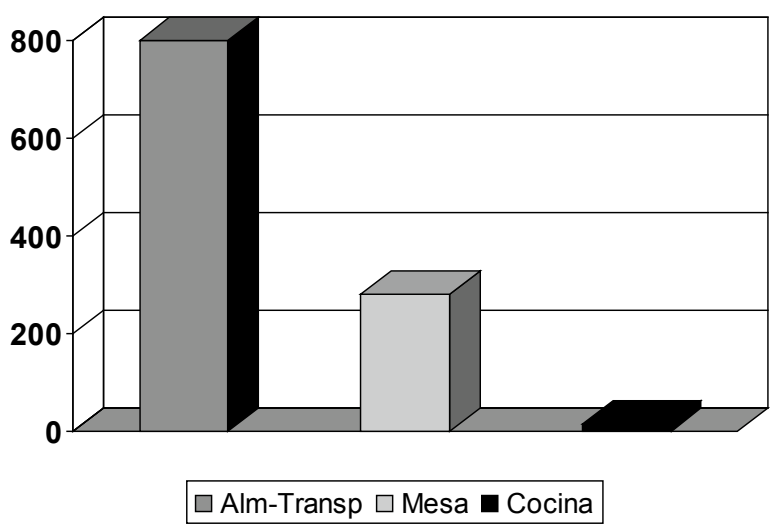

Figura 18: Total de materiales cerámicos.

acababa en este punto $^{11}$, mientras que hacia el oeste ignoramos su trazado más allá de lo conservado. En nuestra opinión, así debería ser, encerrando entre ambos $^{12}$ un espacio abierto o patio de unos $16^{\prime} 80 \times 3^{\prime} 5 \mathrm{~m}$ $\left(59 \mathrm{~m}^{2}\right)$, que hemos, por tanto, de integrar en el estudio del edificio, pues sin duda se diseñó por una necesidad.

\section{ALGUNAS CONSIDERACIONES SOBRE LA CULTURA MATERIAL}

Resulta conveniente cerrar el capítulo material con una breve reflexión final a efectos de considerar a un golpe de vista el tipo de recipientes hallados en este asentamiento, lo que puede ser ilustrativo, en comparación con otros, de su particular idiosincrasia.

En la intervención realizada se han recuperado un total de 1118 restos arqueológicos, todos cerámicos excepto un registro de fauna, tres de malacofauna, otro lítico y la moneda italiana citada. Hay un absoluto predominio de la cerámica de cocción oxidante, estando decorados tan sólo el $8 \%$ de los fragmentos localizados. Considerado el total respecto a su valor funcional, el reparto resultante sería el que sigue (Fig. 18), similar en sus datos a la Figura 7:

El principal grupo funcional es el de almacenajetransporte, compuesto por 816 fragmentos, la gran mayoría de ánforas. La siguiente forma a destacar sería el lebes, contabilizándose seis bordes de este envase, un recipiente de grandes dimensiones que se caracteriza por tener cuerpo globular, sin cuello, gran diámetro en boca, labio en ala y pie anillado. Sus funciones son diversas, aunque es común en el ámbito doméstico para la transformación de alimentos o para su almacenaje. Del resto, hay fragmentos que deben pertenecer a tinajas o tinajillas, uno de ellos una base no decorada, y otros son informes con decoración geométrica pintada. Del total de fragmentos de ánfora recuperados

11. De ser así, es posible que en este «vano» se situara una puerta.

12. Tal vez incluso un tercero por el oeste. 
27 son bordes, adscritos tipológicamente a las tradicionales formas I-3 e I-4 (Ribera, 1982), detectándose en dos bordes y ocho informes la presencia de un escobillado a modo de surcos concéntricos o espiraliformes en la zona de los hombros y arranque de asas, aspecto técnico que nos remite, como ya señalamos, a las denominadas ánforas contestanas. De entre los informes se han contabilizado 32 registros pertenecientes a contenedores púnico-ebusitanos, distinguiéndose pastas ocres y arenosas ricas en mica, otras de fuerte tono anaranjado y unas terceras con frecuente desgrasante; es posible que se correspondan, respectivamente, con orígenes ebusitanos, del Norte de África y del Círculo del Estrecho o área gadirita. Cabe destacar el fragmento de galbo con fuerte y marcada carena, cuya pasta y morfología indica que pertenece al tipo llamado Mañá-Pascual A4, o Tagomago. Presenta una característica pasta sándwich, dura y compacta, con una superficie interior de tono anaranjado y la exterior ocre, cubierta por un fino engobe del mismo color; el desgrasante es frecuente, con partículas de cuarzo y elementos micáceos, además de otras trazas difíciles de identificar sin un análisis específico. Son ánforas de perfil bitroncocónico, con largo cuello cilíndrico o de tendencia cónica y una marcada carena en su transición con la parte inferior del cuerpo, cuya terminación es apuntada, cerrando el cono invertido con un botón o de forma continuada y suave (Fig. 5; UE 100-19).

El grupo funcional de mesa-presentación cuenta con 280 restos cerámicos. De ellos, dieciseis son bordes pintados de platos ${ }^{13}$, decorados en óxido de hierro con motivos geométricos, básicamente bandas, líneas y círculos concéntricos. Se identifican fragmentos del tipo Mata-Bonet III.8.1 (Bonet y Mata, 1992), o platos de borde exvasado, y, sobre todo, del III.8.2, páteras o platos con borde reentrante. También se documenta un pie de copa, posiblemente del tipo III.6, y dos oenochoai tipo III.2, recipientes profundos y cerrados con un asa, normalmente decorados y cuyo uso está directamente relacionado con el contenido y consumo de líquidos.

El tercer grupo funcional representado es el de cocina-fuego. Está compuesto por 16 fragmentos, de diferentes formas de olla y de una cazuela -fragmento de base acanalada-, todos ellos de pasta gris reductora, friable y con núcleo rojizo y frecuentes desgrasantes calizos, apropiada para su uso en el fuego.

Finalmente, en un último grupo de «Varios» incluiríamos un único fragmento de fauna, probablemente un colgante, y tres piezas de malacofauna: una ostra, una barca de sepia y una lapa, de lo que se infiere un ocasional contacto con el litoral de este grupo, o de quienes con ellos se relacionaron. También contabilizamos aquí un fragmento de molino en piedra arenisca, un tejuelo o tapón, recortado sobre un ánfora con forma circular, y la moneda referenciada.

13. Otros cuatro no muestran decoración pintada.
La siguiente tabla resume las cerámicas ibéricas localizadas en el yacimiento de acuerdo con su morfología y el NMI (Fig. 19):

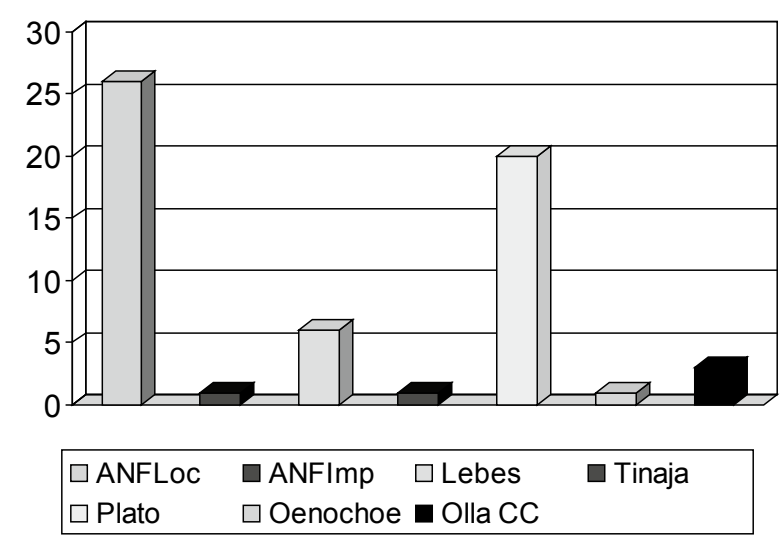

Figura 19: Total de materiales cerámicos por formas según NMI.

Dicha tabla matiza un tanto los datos proporcionados por el volumen total de fragmentos recuperados, pues los recipientes anfóricos locales y los platos se acercan bastante -26 bordes frente a 20 , asumiendo también un mayor protagonismos lebetes y ollas grises. Se conforma, así, un ajuar-tipo para el establecimiento ya referido anteriormente, en el que se incluirían un par de recipientes de almacenaje y/o transporte, uno de mesa y una olla para cocinar. A efectos estadísticos, los primeros supondrían el $59 \%$ del total de los envases cerámicos, la vajilla de mesa el $36 \%$ y los recipientes de cocina el $5 \%$. Finalmente, son de especial transcendencia los fragmentos anfóricos de origen púnico localizados, por referir así los únicos recipientes no locales del conjunto, los cuales alcanzarían un porcentaje del $3 \%$ respecto al conjunto total de piezas recuperadas.

\section{COLMENARES EN SUS CONCLUSIONES}

Las características de esta construcción de unos $55 \mathrm{~m}^{2}$ -o de poco más de $100 \mathrm{~m}^{2}$ si contabilizamos el posible patio trasero- la definen como un edificio único de planta rectangular construido con mampostería no trabajada y subdividido al interior en tres espacios de similar tamaño. Su diseño busca levantar una construcción simétrica y equilibrada en sus proporciones, pero su fábrica y ejecución no alcanzan un acabado esmerado y regular. Ni sus paredes ni sus interiores se acondicionaron, y sólo la aparición de una mancha negruzca hacia el centro de la estancia 2 marcaría con nitidez el nivel interno de circulación; posiblemente, pudo existir un mínimo acondicionamiento del interior mediante materiales perecederos (pieles, madera o simplemente, arbustos), pero ninguna evidencia de ello se ha obtenido (Fig. 20). 


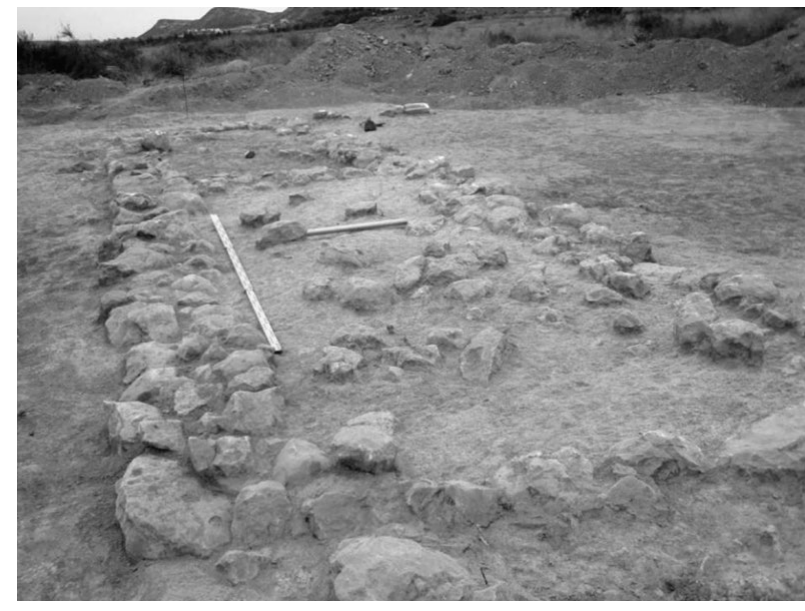

Figura 20: Vista de detalle del Dpto. 2 desde el noroeste.

La regularidad de su trazado aboga por una inspiración en modelos constructivos similares y, de hecho, recuerda las estructuras ad oikoi del mundo clásico (Martin, 1974, 229). No obstante, y a pesar del minucioso rastreo efectuado sobre arquitecturas de época ibérica, no hemos encontrado un paralelo exacto para un edificio a priori de líneas tan sencillas. En La Bastida de les Alcuses, contemporáneo a los restos ahora analizados, hemos localizado la construcción más parecida en cuanto a medidas y concepto arquitectónico, la casa integrada por los departamentos 241 a 243, pero tampoco resulta idéntica. En efecto, se parte de un edificio no excesivamente grande de planta rectangular, que se subdivide al interior en tres estancias de similares proporciones (Bonet y Vives-Ferrándiz, 2011, fig. 1). Sin embargo, en este caso se opta por yuxtaponer las estancias a partir del lado largo, mientras que en Colmenares es el lado corto el que sirve de punto de apoyo para proyectar la construcción, subrayando de este modo el protagonismo que tendría su fachada. Es posible que la distinta funcionalidad de ambos edificios oriente la planta final de la construcción, pues en Bastida sería un espacio de residencia permanente, mientras que en Colmenares su uso como almacén y lugar de producción agrícola podría indicarse como el más probable.

Por lo que se refiere a la funcionalidad concreta de cada una de las estancias, el ajuar cerámico hallado no muestra excesivas diferencias entre sí. En el ambiente 3 sólo aparecen fragmentos de ánfora, mientras que en los otros dos se deduce una vajilla básica con recipientes de mesa - un par de platos-, una olla para cocinar $\mathrm{y}$, sobre todo, envases de almacenamiento y transporte -2-3 ánforas y un lebes-; no se subraya, por tanto, una orientación funcional clara, por lo que habrá que concluir que, desde el punto de vista del registro cerámico, nos encontramos ante estancias donde se deben realizar distintas actividades, con predominio de las tareas de almacenaje.

El resto de evidencias arqueológicas podrían matizar un tanto esta visión, pues parece claro que la actividad que genera los estratos de tierras grises - sin duda una tarea principal en el edificio- se concentra inmediatamente al exterior del ambiente 2, que, además, cuenta con la evidencia de un hogar en su interior. Ello podría indicar una sustancial diferencia en su función respecto a los ambientes 1 ó 3 . Finalmente, la localización en el ambiente 3 de un rehundimiento circular del estrato natural de unos $140 \mathrm{~cm}$ de diámetro, tal vez la huella de algún equipamiento, podría igualmente reorientar su función.

Las distintas variables analizadas -dimensiones del edificio, características constructivas, estratigrafía arqueológica tanto al interior como al exterior o la tipología y volumen de los materiales cerámicos recuperados- orientarían a considerar como probable que estamos ante una construcción cuya ocupación debió ser temporal o estacional, por lo tanto bastante restringida en el tiempo y, en consecuencia, difícilmente utilizada como residencia habitual de una familia.

En párrafos anteriores hemos aludido a su probable definición como, al menos, lugar de almacenaje, dados los elevados porcentajes de recipientes anfóricos localizados. Otras variables nos llevan a considerar la misma posibilidad, por ejemplo su patrón de asentamiento, pues se ubica en una zona casi llana, de amplia tradición agrícola -fundamentalmente cultivos arbóreos de secano y cerealícolas- y bien comunicada a través del Camino Viejo de Elche.

Por todo ello, estimamos como probable que estemos ante una instalación productiva relacionada con la agricultura, aunque no estemos en condiciones de describir con precisión todas las tareas implícitas en esta funcionalidad. Hemos manejado la posibilidad de que sirviera para el procesamiento de cereales o de otro tipo de frutos (como la almendra o la barrilla), e incluso que su topónimo indicara una orientación apícola, como en la Fonteta Ràquia (Mata et alii, 2009), pero en todos los casos existen argumentos en contra: no hay evidencias carpológicas, el registro cerámico no es especializado ${ }^{14}$ o las instalaciones superan en mucho las necesidades de la obtención de sosa. Nos queda el registro mueble y, en él, las ánforas, y los lebetes, indican una fase de almacenamiento, posiblemente de corta duración, pues como señalara N. Alonso, estos recipientes son usados como envases para el transporte y no tienen carácter fijo (Alonso i Martínez, 1999, 227). Luego no debía transcurrir excesivo tiempo entre su relleno y su posterior traslado, es de suponer que hacia el oppidum más cercano. En consecuencia, el edificio serviría como núcleo para realizar un primer almacenamiento de la cosecha ¿apícola?, que

14. La Dra. F. Sala nos ha hecho ver la posibilidad de la existencia de envases de material perecedero, concretamente colmeneros realizados en esparto, hipótesis que no es de descartar. Sus sugerentes apuntes, aportados en este tema y en otros relacionados con la cultura material, sin duda han enriquecido el texto final. 
suponemos se obtendría de los terrenos inmediatos. Aquí debía realizarse un primer proceso de transformación del producto, seguramente relacionado con las evidencias de fuego documentadas, siendo la materia resultante introducida en ánforas para su traslado. De este modo, el edificio ahora excavado podría conjugar los usos propios de un almacén y de un área de transformación anexa ligada al fuego, función que, en cualquier caso, parece bastante delimitada en el tiempo, posiblemente coincidiendo con un periodo de máxima actividad agraria y que, incluso, pudo derivar parte de esta producción a su comercialización.

A propósito de la datación del edificio, el registro documentado muestra una escasa variabilidad en sus tipos, a lo que hay que añadir la casi absoluta inexistencia de material importado -reducido éste a los fragmentos anfóricos púnico-ebusitanos, ninguno de los cuales se corresponde, además, con el borde del recipiente-, siendo especialmente flagrante la ausencia de vajilla importada, como por otro lado parece razonable, habida cuenta la función de la construcción.

Queda, por tanto, el repertorio estrictamente ibérico para proponer un encuadre histórico y es de general conocimiento que, por el momento, no podemos precisar en exceso las secuencias de aparición y desarrollo de la mayoría de las cerámicas ibéricas locales, a pesar de los numerosos y loables intentos realizados al respecto en los últimos años, algunos de los cuales han alcanzado una notoria trascendencia (Mata y Bonet, 1992; Sala, 1995; Bonet y Mata, 2008).

En este contexto, creemos más apropiado para nuestros intereses seguir la senda marcada por el trabajo de F. Sala (1995), más enraizada en secuencias estratigráficas concretas y cercanas al hito ahora analizado. Creemos, en efecto, que el camino para realizar series tipológicas, cuales sean, debe iniciarse desde horizontes arqueológicos muy particulares, para ir extendiéndolos progresivamente tanto en el espacio como en el tiempo. La tipología de F. Sala tiene esta virtud: parte del conocimiento riguroso y completo de los contextos materiales de tres asentamientos ibéricos (El Oral, La Escuera y Puntal de Salinas), bien datados, prácticamente correlativos y que, además, se ubican en comarcas cercanas. De este modo, se puede precisar el ajuar cerámico de un determinado poblado en un periodo dado, obteniendo un «aire de familia» tipológico y forma ${ }^{15}$ útil para la comparación y la búsqueda de caracteres globales, aprehendiendo sus elementos característicos, los que definen las distintas facies ibéricas.

Aplicados estos al registro del asentamiento ahora estudiado, llama la atención la ausencia absoluta de algunos tipos -como la cerámica fina gris, recurrente en el horizonte ibérico antiguo-, o la presencia de

15. Incluiríamos el factor decorativo si no fuera porque todos los fragmentos pintados hallados en la excavación son de temática geométrica sencilla. algunas formas específicas, como la fuente de asas de espuerta o el kalathos de cuello estrangulado ${ }^{16}$, la primera datada entre los ss. VI y IV aC y el segundo en los ss. IV-III a.C. A ello podríamos añadir la presencia de varias huellas de escobillado en los hombros de ánforas ibéricas que, como señalamos, han venido a servir de argumento para definir una producción local de los ss. IV-III aC -las ánforas contestanas (Álvarez, 1997, 152)-, envases manufacturados en los alfares de La Illeta de El Campello y, posiblemente, en el área del Cerro de las Balsas-Tossal de Manises y el entorno inmediato de La Alcudia de Elche (López Seguí, 2000). Las dataciones solapadas apuntan a una ocupación para el edificio de la sierra de Colmenares desarrollada a lo largo del siglo IV aC, cronología que podríamos intentar precisar hacia su primera mitad.

En este sentido, las ollas de cocina con el cuello decorado con líneas incisas están perfectamente representadas en asentamientos cercanos de la fase antigua, como El Oral (Abad y Sala, 1993; Abad et alii, 2000), y también este yacimiento ha deparado el hallazgo de las ánforas tipo Tagomago o Mañá-Pascual A4, que J. Ramón ha encuadrado como tipo T-11.2.1.3 (Ramón, 1995). Subrayamos que en Colmenares tan sólo hemos hallado un fragmento de la carena del envase, faltando cualquier otro elemento formal del mismo; en cualquier caso, el grosor del fragmento y el acusado quiebro que realiza permite proponer su pertenencia al tipo referido. Su pasta apunta, en este caso, a un origen en la provincia sedimentaria peninsular, de alfares indeterminados del Mediterráneo Occidental o de la bahía gaditana. Sin entrar en esta difícil problemática, la cuestión que nos interesa es la cronológica, pues el ánfora Tagomago es el tipo característico del s. V aC, siendo sustituido por otros envases en el tránsito entre esta centuria y el IV aC, como demostraría su aparición en El Puntal de Salinas.

En conclusión, el aire de familia del repertorio cerámico localizado y los indicios formales que acabamos de comentar, nos llevan hacia una cronología de principios del $\mathrm{s}$. IV aC, o incluso finales del $\mathrm{V} \mathrm{aC}$, para la construcción del edificio levantado en la umbría de la sierra de Colmenares, desarrollándose su ocupación -que no creemos se extendiera más allá de un par de generaciones- a lo largo de la primera mitad del s. IV $\mathrm{aC}$.

\section{EL EDIFICIO EN EL CONTEXTO HISTÓRICO DEL IBÉRICO PLENO}

El asentamiento de Colmenares, a pesar de la escasa variedad de su registro cerámico y su modesto tamaño, proyecta una indudable trascendencia sobre el modelo de poblamiento comarcal, no tanto por su función

16. Ambos se hallaron en las tareas de prospección superficial que localizaron el asentamiento. 
-pues se conocen otros almacenes en el ámbito ibérico alicantino- sino, sobre todo, por su carácter de construcción aislada en el llano, alejada de cualquier núcleo urbano conocido que pudiera ejercer un control directo sobre la misma. En este sentido, el yacimiento ibérico más cercano a Colmenares, y no es segura su sincronía con él ${ }^{17}$, sería Fontcalent, situado hacia el norte a casi $7 \mathrm{~km}$ de distancia en línea de aire. A unos $11 \mathrm{~km}$ al este quedaría el Cerro de las Balsas y, ya en término ilicitano, La Moleta se localiza a unos 12 $\mathrm{km}$ hacia el oeste ${ }^{18}$, estos dos últimos con garantías de estar ocupados durante el s. IV aC (Moratalla, 2003 y 2005). Es decir, se trata de un hito que no manifiesta una clara relación de dependencia con núcleo ibérico alguno, considerando el factor distancia como determinante para esta inferencia; de hecho, queda prácticamente a mitad de camino entre dos oppida -11-12 $\mathrm{km}-\mathrm{y}$ ésta es su gran singularidad, al tratarse, además, de un núcleo de llanura, que prescinde casi por definición y desde su planificación de elemento de defensa alguno.

Es de subrayar, por otro lado, su cercanía al eje caminero que ha unido tradicionalmente Alicante y Elche, el tan referido Camino Viejo de Elche. La distancia hasta el mismo desde el asentamiento ronda los $500 \mathrm{~m}$, lo que sin duda favorecía la accesibilidad a la zona, casi como si fuera una posta o parada en el trayecto. Seguramente se consideró la cercanía a esta vía de comunicación como factor trascendental a la hora de construir el edificio y es posible, incluso, que se levantara en medio de campos cultivados, cuyos productos o parte de los cuales tendrían en el edificio su destino inmediato. En cualquier caso, y al margen de otro tipo de consideraciones sobre la organización y el control del territorio entre los oppida ibéricos, su presencia demuestra, como poco, la constatación de una continuidad en la ocupación del territorio entre dos importantes ciudades ibéricas, como serían las emplazadas en la bahía de La Albufereta, en Alicante, y en La Alcudia, de Elche, intercalada en el trayecto, en acertada expresión de A. Moreno (Moreno, 2011). Y dicha porción territorial es ocupada durante un lapso de tiempo determinado sin considerar prácticamente variables estratégicas, como la defensa del establecimiento, de lo que hemos de inferir que esta cuestión quedaba cubierta, al menos en esta época, bien por la comunión de intereses entre las comunidades que habitaban a uno y otro lado de la sierra, o bien porque

17. En efecto, una actuación arqueológica realizada en 2008 por la empresa ARQUEALIA en este yacimiento permitió documentar materiales cerámicos de un amplio segmento cronológico, que comprende desde un horizonte del Bronce Final hasta época visigoda; a pesar de esta larga secuencia y los miles de fragmentos inventariados, el porcentaje de cerámicas áticas es ínfimo, cuando están muy bien documentadas importaciones de otras épocas, por lo que es cuestionable su ocupación durante el s. IV aC.

18. La Alcudia de Elche quedaría a $14 \mathrm{~km}$ al sudoeste. directamente resultaba innecesaria, o ambas cosas a la vez. En cualquier caso, coincidiría con un periodo de máxima expansión demográfica ibera para estas tierras (Moratalla, 2003 y 2005).

Esta primera reflexión nos conduce sin remedio a la consideración del hábitat en llano en época ibérica plena, cuestión en la que se atisban profundas transformaciones respecto a las consideraciones teóricas que hemos conocido en las últimas décadas, y de las que nosotros mismos hemos participado. En efecto y en lo que se refiere a las tierras valencianas, los pioneros trabajos del equipo dirigido por J. Bernabeu para el Camp del Turia (Bernabeu et alii, 1987) establecieron un modelo de poblamiento en el que, más allá de los oppida, se extendía una red de asentamientos agrupados bajo conceptos un tanto genéricos de granjas, caseríos, aldeas o atalayas. Análisis posteriores siguieron esa senda trazada (por ejemplo y para estas tierras Grau, 2002; Moratalla, 1999 y 2005), al igual que ocurría en otras áreas peninsulares ibéricas, que ofrecerían también un largo listado bibliográfico. Sin embargo, la realidad arqueológica se constata progresivamente mucho más compleja de lo que preveíamos.

El avance de la investigación arqueológica a propósito de los asentamientos en llano en lo que llevamos de s. XXI, ligado en buena medida al desarrollo de grandes infraestructuras o proyectos inmobiliarios, ha venido a demostrar que esos presupuestos teóricos erraban en gran medida -como ya se venia demostrando en intervenciones arqueológicas de similar naturaleza (Vidal et alii, 2004) - en cuestiones tan fundamentales como el tamaño de los yacimientos y su función, dos pilares básicos sobre los que descansan las hipótesis sobre la red de poblamiento en una cultura y momento dados. Colmenares es paradigmático en este sentido: de haber sido localizado tiempo atrás y permaneciera sin excavar, hubiera sido calificado muy probablemente como un caserío de media hectárea de tamaño, con una indudable proyección sobre el terreno circundante. Pero la realidad, con frecuencia, resulta un tanto más anodina y aquella perspectiva se reduce a una única construcción que ocupa la décima parte de la extensión que abarcaba el registro cerámico superficial.

Esta consecuencia nos conduce a dos reflexiones inmediatas, una primera la más obvia -la estructura del territorio cuenta con una mayor variedad de tipos de hábitat de los que se presuponían- y otra segunda de mayor calado: si los modelos de poblamiento hasta ahora propuestos, y sus derivaciones socio-políticas, descansan, entre otras cosas, en una estructura territorial rígida de carácter jerárquico, ¿cabría replantearse esta interpretación a la vista de modelos probablemente no tan encorsetados? Posiblemente no, los oppida siguen existiendo y los signos e indicios en ese sentido son numerosos, aunque quizás, precisamente, no acabamos de leer a la perfección esos signos.

Colmenares, en su modestia, nos ofrece respuestas, y un buen puñado de preguntas, sobre cómo se 
estructura un territorio ibérico, y el hilo argumental de éste son sus caminos tradicionales, como el Camino Viejo de Elche. La vinculación del asentamiento con este eje nos ofrece pocas dudas, de ahí que le atribuyamos una datación tan antigua como la del propio asentamiento; su cercanía, la orientación de la fachada, ofreciéndose desde la distancia al caminante, su emplazamiento estratégico - a mitad de la ruta, poco antes de salvar El Portichuelo-, son datos que nos permiten avalar esta vinculación. En ese punto se levanta un edificio de líneas constructivas prediseñadas, inserto en el secano y no excesivamente alejado de un paso que salvaba la sierra de Colmenares por su punto más factible. No cuenta con obra complementaria alguna que garantizara su defensa, luego quedaba a la vista desde la distancia sin que, al parecer, su integridad corriera peligro. El dato trascendente no es si está fortificado o no, pues ya conocemos otros asentamientos de llano que carecen de estas obras, lo realmente destacable es que no tiene al alcance inmediato un oppidum en sentido estricto.

Esta construcción responde a un plan muy concreto, aunque resulta difícil determinar su origen y las razones últimas de su emplazamiento. Es obvio que esta unidad productiva debe ser, o al menos lo fue un tiempo, un eslabón de un tejido más amplio, pero, sin oppidum de referencia inmediato, se complica adscribirlo a una decisión emanada directamente de un centro de decisión determinado. Pudo derivar de una planificación más «regulada», pero tampoco acertamos a ver porqué no respondería a un episodio más, digamos, espontáneo. La documentación arqueológica apunta a un edificio levantado para llevar a cabo una función determinada y que, al parecer, en unas décadas se abandonó. Su fábrica es similar a la de los muros de los poblados contemporáneos, caracterizándose la planta por la simpleza de líneas y la modestia en equipamientos. Debió ser ocupada para llevar a cabo actividades diurnas muy posiblemente relacionadas con el campo, para presumiblemente volver a sus hogares a la noche, localizados en ese desconocido oppidum. Sin duda pueden ser campesinos, sin que insistamos más sobre el grado de servidumbre que pudieron padecer, que al parecer conocieron una época de bonanza en el plano demográfico y una mínima estabilidad territorial.

Ésta es la base empírica, y ahora que comenzamos a ver los nuevos documentos, podría ser oportuno reformular los patrones tradicionales sobre el poblamiento ibérico, o al menos proponer una visión del paisaje más allá del oppidum. A partir de ahora y una vez vayan siendo excavados, habrá que contar con la presencia de grupos, en ocasiones muy poco numerosos, que se mueven por el territorio más allá de las fronteras inmediatas del oppidum, y habrá que analizar cómo se integran, con qué status, en el colectivo al que pertenecen, si es que pertenecen a alguno, que parece probable que sea así. Un vistazo a alguno de estos pioneros trabajos sobre los asentamientos ibéricos en llano, que, además, nos permitirá comprobar la variabilidad de los mismos, resulta elocuente de las dificultades interpretativas que vienen generando sobre su naturaleza y proyección social.

En los territorios ibéricos de Kelin y Edeta es donde podemos observar un mayor avance en el estudio de este tipo de hábitats y ya podemos contar con varios hitos que pasarían a engrosar la categoría, un tanto genérica, de «hábitats productivos temporales» o enclaves rurales. También se conocen ejemplos de asentamientos dispersos en Cataluña, si bien, en general, no suelen coincidir con la naturaleza del ahora tratado, ya sea por la presencia inmediata de grandes oppida, como Ullastret o Burriac, ya por estar estrechamente vinculados a campos de silos, o ya por ser de datación tardoibérica (Plana y Crampe, 2004; Zamora, 2012). Merece la pena recordar, no obstante, el ejemplo de la granja de Fondo Roig (García et alii, 2003), aunque en este caso estamos ante un conjunto de una complejidad estructural muy superior a la ahora analizada.

En tierras valencianas, los trabajos de campo de los últimos años de los equipos que dirigen $\mathrm{H}$. Bonet y $\mathrm{C}$. Mata (Bonet et alii, 2008; Jardón et alii, 2009; Mata et alii, 2009; Moreno, 2011) ya han puesto de manifiesto la complejidad estructural del hábitat ibérico de llanura, habiéndose excavado varios yacimientos en la zona que responderían a este modelo de asentamiento en llano, por lo general de muy pequeña talla y modestas construcciones y con un registro cerámico muy funcional. Entre ellos encontramos una variada gama de establecimientos, desde los que presentan sólo fosas o algunos muros aislados -Casa de Ángel, La Cabezuela, Els Clots y L'Aljub Nou- hasta los más complejos, que incluyen un edificio completo -El Zoquete- o equipamientos del tipo lagar -Rambla de la Alcantarilla-, pasando por los que sólo presentan alguna infraestructura del tipo horno además de un departamento de piedra o caseta -Cerro Tocón-. A destacar, además, La Fonteta Ràquia, un edificio también rectangular y con similar orientación a Colmenares compartimentado en cinco-seis estancias, para el que se propone una función relacionada con el aprovisionamiento de miel, y ciertamente resulta significativa la abundancia en el lugar de los recipientes identificados como colmeneros. Con esa cierta identidad de planta entre ambos y con Colmenares como topónimo, de haber encontrado ahora un registro parecido, podríamos haber alcanzado conclusiones similares.

Son asentamientos, en definitiva, que incluyen bodegas, talleres, almacenes, pequeños caseríos, etc, y que ocupan un terreno bastante reducido e incluso recóndito, en ocasiones alejados de los centros principales, y que se identifican como lugares de explotación agraria no residenciales, levantados por «los propietarios de los campos adyacentes» (Mata et alii, 2009, 149-150). A partir de esta conclusión, se propone un modelo interpretativo sobre la organización socio-política de la producción, concluyendo que serían «Casas ofamilias que persiguieron la creación y el mantenimiento de estatus, riqueza o poder», es decir, según 
deducimos, actuarían con cierta autonomía respecto al centro principal, sobre todo en el territorio de Kelin.

En otra línea de interpretación parecen situarse los excavadores de un conjunto arqueológico de aire similar a los que ahora tratamos aquí, L'Altet del Punxó, en la comarca de El Comtat (Espí et alii, 2009), lo que demuestra su dificultad interpretativa. Se trata de un área arqueológica distribuida en terrazas fluviales de, al parecer, no menos de 1 Ha de extensión, donde se solapan en el tiempo varios fondos de cabaña y restos constructivos de piedra definiendo estancias aisladas, sin duda relacionadas con la producción de cereales, a tenor de las numerosas evidencias halladas de molinos rotatorios. Se interpretan como residencias temporales, ligadas al ciclo del campo, en un conjunto que califican como «hábitats semipermanentes que sólo pueden enmarcarse en un contexto de existencia de territorios apropiados y delimitados por la comunidad que reside permanentemente en otros lugares». Y se añade poco después que «el señor concedería los derechos de uso del suelo a las familias campesinas a cambio de la filiación al linaje, con el pago de un tributo» (Espí et alii, 2009, 45-46). Como se puede comprobar, resulta una lectura bastante opuesta a las realizadas en tierras del Túria, también porque el registro es diferente, pues la presencia diríamos casi «industrial» de los molinos rotativos indicaría ciertamente una producción por encima del autoabastecimiento. Pero también se admite que estos campesinos consumieron bienes de prestigio, lo que cuesta encajar en las interpretaciones históricas que subrayan las diferencias de rango entre los iberos.

Ambos ejemplos - a los que podrían añadirse otros de tierras catalanas y murcianas- plantean la seria dificultad de interpretar estos hábitats en términos de control político, económico y social. Parece factible que se estableciera algún tipo de estrategia colectiva cuando un hábitat secundario o temporal queda a tiro de piedra del oppidum, pero más allá de un radio razonable de 4-5 km, se nos antoja difícil de admitir que el uso, que no posesión, de la tierra estuviera sujeto a un control absoluto de dicho lugar central. Nos parece más sensato suponer que el acceso a aquélla fuera permitido por la colectividad, sobre todo, como sería el caso de Colmenares, cuando no estamos ante un terreno especialmente feraz para la agricultura u otras materias primas y que, además, queda prácticamente en el límite teórico entre dos grandes territoria (Fig. 21). Al socaire del camino, se estableció una construcción aislada para obtener seguramente un recurso muy propio y conocido de la zona, o incluso exclusivo de ella, y no hay indicios que permitan plantear que responde a una especie de colonización planificada. Por tanto, vislumbramos un paisaje rural más en la línea de lo apuntado para el territorio de Kelin: grupos de trabajo posiblemente con vínculos familiares que, de acuerdo con las características del producto obtenido, se trasladan temporalmente desde un lugar central alejado a un edificio que pueden haber construido ellos mismos, para obtener un rendimiento, de la tierra o de su entorno inmediato, con el que poder comerciar en ámbitos locales -de hecho, tienen acceso a envases púnicos-y elevar, así, sus rentas. Este establecimiento parece haber hecho las veces de almacén y lugar de recogida de sus ocupantes temporales, y ésta sería la interpretación que nos resulta más razonable y acorde al registro arqueológico obtenido, sin menoscabo de que estas fórmulas productivas puedan convivir con otro tipo de servidumbres que, en este caso, no captamos.

La experiencia que vamos acumulando nos aconseja no asimilar, sin más, un determinado tipo de estructura territorial bajo parámetros excesivamente fijos,

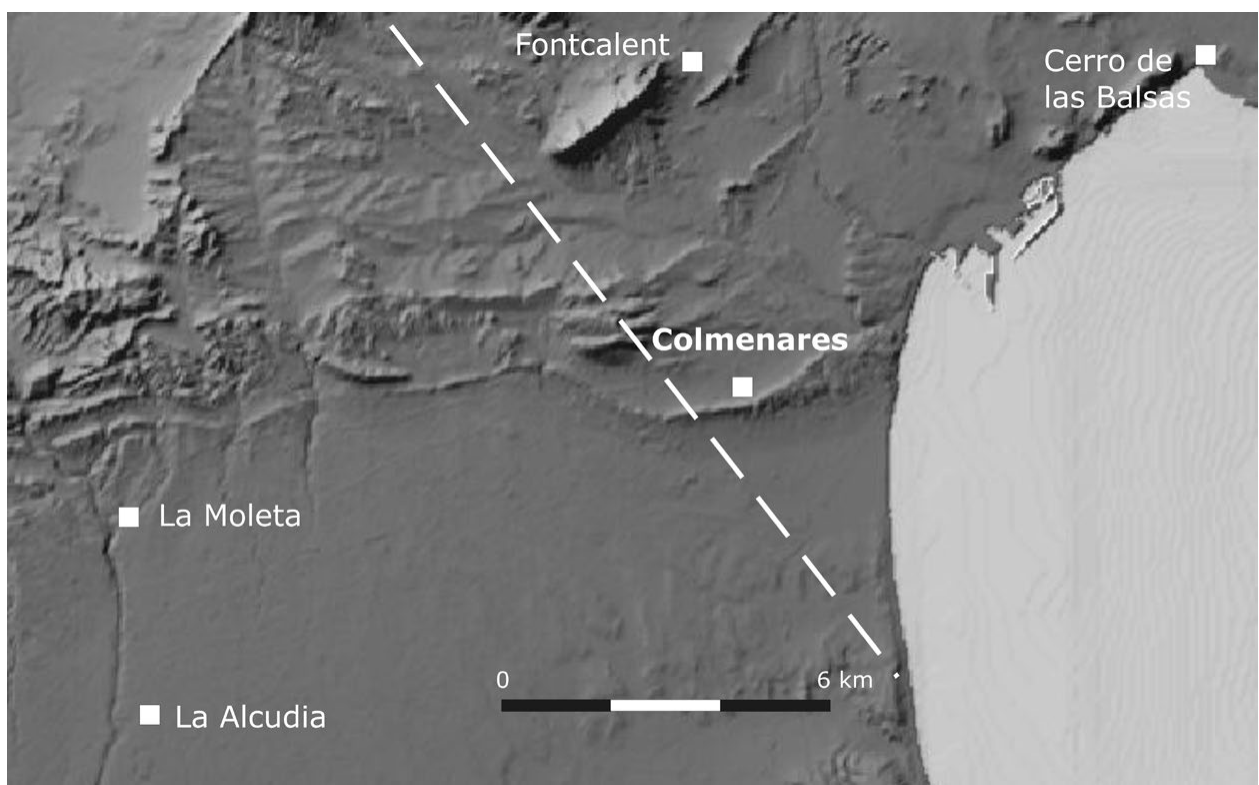

Figura 21: Distribución del hábitat ibérico en el entorno de Colmenares; la línea discontinua marca la divisoria teórica de territorios entre La Alcudia y Cerro de las Balsas, de acuerdo con los polígonos de Thiessen. 
por lo que puede ser oportuno dar cabida a otras lecturas más heterodoxas si se quiere, o al menos matizar aquellos planteamientos iniciales que prácticamente establecían un modelo de poblamiento unívoco sin apenas haber excavado sus asentamientos. El poder de coerción de las oligarquías iberas era limitado, por eso la distancia entre los oppida del territorio ibero apenas supera la decena de kilómetros en muchos casos, y este poder obviamente decrece conforme nos alejamos del lugar central. Un asentamiento situado a más de $11 \mathrm{~km}$ del supuesto lugar central y a la vuelta de una colina en la que entraríamos en el territorio del siguiente, tiene escasas posibilidades de ser controlado desde el primero. Por ello, creemos que los modelos interpretativos de instauración territorial deben acoger fórmulas que permitan la ocupación de nichos particulares, por lo general con carácter temporal, más allá del control efectivo que se puede ejercer sobre el territorio inmediato al oppidum, y, por tanto, escapando en cierto modo a ese teórico control férreo que pudiera desprenderse de dicho lugar central. Posiblemente una de las conclusiones que nos parecen más juiciosas para el análisis de los restos ahora tratados es que su sola presencia permite inferir una cierta estabilidad para el territorio del sur de la Contestania en época plena, donde es posible la existencia de estos asentamientos liminares como Colmenares, a su vez un claro indicio de que las comunidades que habitaban a uno y otro lado del Portichuelo participan, sin duda, de unos lazos o intereses comunes que favorecieron la existencia de estos asentamientos que nos atrevemos a calificar como espontáneos u oportunistas por parte de pequeños grupos.

Prof. Dr. Jesús Moratalla Jávega
Área de Arqueología
Dpto. Prehistoria, Arqueología, Hª Antigua,
Filología Griega y Filología Latina
Facultad de Filosofía y Letras
Universidad de Alicante
03080 Alicante
jesus.moratalla@ua.es
Gabriel Segura Herrero
Arquealia
c/ Pablo Iglesias, 124
03600 Elda
gsegura@arquealia.es

\section{BIBLIOGRAFÍA}

ABAD CASAL, L. y SALA SELLÉS, F., 1993: El poblado ibérico de El Oral (San Fulgencio, Alicante), Trabajos Varios del S.I.P. 90, Valencia.

ABAD CASAL, L., SALA SELLÉS, F. (Eds.), GRAU MIRA, I., MORATALLA JÁVEGA, J., PASTOR MIRA, A. y TENDERO PORRAS, M., 2000: Poblamiento ibérico en el Bajo Segura. El Oral (II) y La Escuera, Bibliotheca Archaeologica Hispana 12, Madrid.

ALONSO I MARTÍNEZ, N., 1999: De la llavor a la farina. Els processos agrícoles protohistòrics a la Catalunya occidental, Monographies d'Archéologie Méditerranéenne 4, Lattes.

ÁLVAREZ GARCÍA, N., 1997: «El Almacén del Templo A: aproximación a espacios constructivos especializados y su significación socio-económica», en $\mathrm{M}$. H. OLCINA DOMÉNECH (Coord.): La Illeta dels Banyets (El Campello, Alicante): estudios de la Edad del Bronce y época Ibérica, 133-170, Alicante.

BERNABEU, J., BONET, H. y MATA, C., 1987: «Hipótesis sobre la organización del territorio edetano en época Ibérica Plena: el ejemplo del territorio de Edeta/Llíria», Iberos, I Jornadas sobre el Mundo Ibérico (Jaén, 1985), 137-156, Jaén.

BLASCO GARCÍA, C., FERNÁNDEZ CURSACH, J., NAVARRO BELMONTE, C. y SERRANO JAÉN, J., 1999: Documents per a la historia d'Elx (De la islamització a les darreries de l'antic règim), Elx.

BONET ROSADO, H. y MATA PARREÑO, C., 2008: «Las cerámicas ibéricas. Estado de la cuestión», en D. BERNAL CASASOLA y A. RIBERA LACOMBA (Eds.): Las cerámicas Hispanorromanas. Un estado de la cuestión, 147-169, Cádiz.

BONET ROSADO, H. y VIVES-FERRÁNDIZ SÁNCHEZ, J. (Eds.), 2011: La Bastida de les Alcuses. 1928-2010, Valencia.

BONET, H., MATA, C. y MORENO, A., 2008: «Iron Age Landscape and Rural Habitat in the Edetan Territory, Iberia (4th-3rd centuries bc)», Journal of Mediterranean Archaeology, 21.2, 165-189.

COELLO, F., 1859: Atlas de España por provincias. Alicante, Madrid.

ESPÍ PÉREZ, I., GRAU MIRA, I., LÓPEZ SEGUÍ, E. y TORREGROSA GIMÉNEZ, P., 2009: «La aldea ibérica de l'Alt del Punxó: producción agrícola y asentamiento campesino en el área central de la Contestania, Lucentum, XXVIII, 23-50.

DEL ESTAL, J. M., 1990: Corpus documental del reino de Murcia bajo la soberanía de Aragón (1296-1304/05), Alicante.

FLETCHER VALLS, D. y SILGO GAUCHE, L., 1992: «El plomo ibérico escrito Serreta I. Comentarios y traducciones», Recerques del Museu d'Alcoi, 1, 9-36.

FERRER I MALLOL, Ma T., 1988: La frontera amb l'Islam en el segle XIV: cristians $i$ sarraïns al País Valencià, Barcelona.

GARCÍA SEMPERE, M., 1990: «Alguns possibles topònims àrabs a la partida de Bacarot (municipi d'Alacant)», Sharq Al-Andalus, 7, Univ. Alicante, 171-174.

GRAU MIRA, I., 2002: La organización del territorio en el área central de la Contestania Ibérica, Alicante.

GUMUZZIO, J. y MATARREDONA COLL, E., 1983: Formaciones edáficas del Campo de Alicante, Alicante.

JARDON, P., QUIXAL, D., MATA, C., NTINOU, M. y PASCUAL, G., 2009: «La Fonteta Ràquia: une installation apicole du siècle $\mathrm{III}^{\mathrm{e}}$ av. J.-C. dans la péninsule Ibérique», Lunula. Archeologia protohistorica, XVII, 193-200.

LLOBREGAT CONESA, E. A., 1991: Ilucant. Un cuarto de siglo de investigación histórico-arqueológica en tierras de Alicante, Alicante. 
LÓPEZ SEGUÍ, E., 2000: «La alfarería ibérica en Alicante. Los alfares de La Illeta dels Banyets, La Alcudia y El Tossal de Manises», II Reunión sobre Economía antigua de la Península Ibérica «Ibers: agricultors, artesans i ramaders» (Valencia, 1999), Saguntum extra 3, 241-248.

MARTÍN, R., 1974: L'urbanisme dans la Grèce antique, Paris.

MATA PARREÑO, C. y BONET ROSADO, H., 1992: «La cerámica ibérica: ensayo de tipología», Trabajos Varios del S.I.P. (Homenaje a E. Plà), 89, 117-173, Valencia.

MATA C., MORENO, A., PÉREZ, G., QUIXAL, D. y VIVES-FERRÁNDIZ, J., 2009: «Casas y cosas del campo: hábitat agrícola y estructura social en los territorios de Edeta y Kelin (siglos V-III a.n.e.)», en M. C. BELARTE (Ed.), L'espai domèstic i l'organització de la societat a la protohistòria de la Mediterrània occidental (Ier mil·lenni aC), Actes de la IV Reunió Internacional d'Arqueologia de Calafell (març, 2007), ArqueoMediterrània $11,143-152$.

MORATALLA JÁVEGA, J., 1999: «La tecnología del hierro como fundamento del crecimiento económico de época ibérica clásica: el ejemplo del sur de Alicante», II Congreso de Arqueología Peninsular (Zamora, 1996), t. III, 375-387, Zamora.

MORATALLA JÁVEGA, J., 2003: Organización del territorio y modelos de poblamiento en la Contestania ibérica, Tesis Doctoral inédita, Universidad de Alicante, Consulta digital en http://hdl.handle.net/10045/3751.

MORATALLA JÁVEGA, J., 2005: El territorio meridional de la Contestania», Jornadas «La Contestania ibérica, treinta años después» (Alicante, 2002), 91-117, Alicante.
MORENO MARTÍN, A., 2011: Cuando el paisaje se convierte en territorio: aproximación al proceso de territorialización ibero en la Plana d'Utiel, Valencia (ss. VI-II ane), BAR International Series 2298, Oxford.

MOROTE BARBERÀ, G., 2002: La Vía Augusta y otras calzadas en la Comunidad Valenciana, Diputación Provincial de Valencia, Serie Arqueología 19, 2 vols, Valencia.

PLANA, R. y CRAMPE B., 2004: «El poblamiento rural a l'entorn de l'oppidum d'Ullastret: l'hàbitat de tipus polinuclear», Cypsela, 15, 251-264.

RAMÓN TORRES, J., 1995: Las ánforas fenicio-púnicas del Mediterráneo central y occidental, Colecció Instrumenta 2, Barcelona.

RIBERA LACOMBA, A., 1982: Las ánforas prerromanas valencianas. Fenicias, ibéricas y púnicas, Trabajos Varios del S.I.P. 73, Valencia.

RIGO, A., FERRER, C., MORER, J. y GARCÍA, J., 2003: «El Fondo del Roig (Cunit): un nucli camperol ibèric de la Cossetània», en M PREVOSTI, J. GUITART y J. PALET (Dirs.), Territoris antics a la Mediterrània i a la Cossetània oriental, 339-348, Barcelona.

SALA SELLÉS, F., 1995: La cultura ibérica de las comarcas meridionales de la Contestania entre los siglos VI y III a. de C. Una propuesta de evolución, Alicante.

VIDAL, F. X., MARTÍ, M A., MATA, C. y BARRACHINA, A., 2004: «De la prospección a la excavación», $A r$ queología Espacial, 24-25, 145-164.

ZAMORA, D., 2012: «L'espai periurbà de l'oppidum laietà de Burriac. De l'Ibèric Ple a la Romanització», C. BELARTE y R. PLANA (Eds.), El paisatge periurbà a la Mediterrania occidental durant la protohistoria y l'antiguitat, ICAC, 149-164, Tarragona. 